\title{
Nomenclatura brasileira para laudos cervicais e condutas preconizadas - Recomendações para profissionais de saúde*
}

\author{
Brazilian nomenclature for cervical cytology reports and guidelines
}

\section{APRESENTAÇÃO}

Os elevados índices de incidência e mortalidade por câncer do colo do útero no Brasil justificam a implementação das ações nacionais voltadas para a prevenção e o controle do câncer (promoçãa, prevenção, diagnóstico, tratamento, reabilitação e cuidados paliativos), com base nas diretrizes da Política Nacional de Atenção Oncológica.

O número de casos novos de câncer do colo do útero esperado para o Brasil, em 2006, é de 19.260, com um risco estimado de 20 casos a cada 100 mil mulheres. Sem considerar os tumores de pele não-melanomas, o câncer do colo do útero é o mais incidente na região Norte (22/100.000). Nas regiōes Sul (28/100.000), Centro-Oeste (21/100.000) e Nordeste (17/100.000), representa o segundo tumor mais incidente. $\mathrm{Na}$ região Sudeste, é o terceiro mais freqüente $(20 / 100.000)$ (Ministério da Saúde, 2006) ${ }^{1}$.

Considerando a necessidade de incorporar novas tecnologias e conhecimentos clínicos, morfológicos e moleculares, com a atualização da Nomenclatura Brasileira para Laudos Cervicais e Condutas Preconizadas, o Instituto Nacional de Câncer, em parceria com os diversos segmentos da sociedade científica, vem promovendo, desde 2001, encontros, oficinas, seminários, grupos de trabalho e grupo focal, ampliando o fórum de discussão e reunindo as contribuições da sociedade para o seu aperfeiçoamento. Objetivando abrangência das discussōes e contribuiçōes dos diversos segmentos da sociedade, o Ministério da Saúde, por meio da Área Técnica da Saúde da Mulher e do Instituto Nacional de Câncer, submeteu à consulta pública o referido documento.
O texto final retrata o resultado desses encontros de trabalho e da consulta pública, buscando estabelecer, com base em evidências científicas, condutas destinadas ao Sistema Único de Saúde (SUS). No entanto, sabe-se que a incorporação de novas tecnologias ocorre de forma gradual e, basicamente, depende da adoção da nova terminologia na rotina diária dos profissionais de saúde, fonte de alimentação do conhecimento.

Essas diretrizes visam a orientar as condutas preconizadas em mulheres com alterações no exame citopatológico cervical. É importante ressaltar que essas diretrizes são o resultado do consenso entre as sociedades científicas e especialistas na área e não têm caráter limitante, mas devem ser encaradas como recomendações que, à luz do conhecimento científico atual, aplicam-se à maioria dos casos clínicos típicos. Apesar disso, cabe sempre ao médico a decisão da conduta a adotar, com base na sua experiência profissional e nas melhores evidências científicas, tendo o compromisso com a boa prática clínica. Portanto, a recomendação de diretrizes para a prática clínica não deve diminuir a capacidade global de decisão e a responsabilidade do médico. Tendo em vista os contínuos avanços da ciência, tornam-se necessárias constantes revisões e atualizaçōes dessas diretrizes.

Agradecemos a todos os profissionais de saúde que contribuíram para essa publicação, nas várias etapas, e pelas valiosas contribuições técnicas que levaram à elaboração desse documento. Nosso reconhecimento especial aos colegas que, com as diferentes experiências profissionais, permitiram um amplo enfoque no seu conteúdo e uma seqüência didática na sua apresentação e à Fundação Oncocentro de São Paulo pela cessão de parte do conteúdo do documento.

"Texto publicado simultaneamente pela Revista de APS - Atenção Primária à Saúde, Revista Brasileira de Ginecologia e Obstetrícia, Jornal Brasileiro de Patologia e Medicina Laboratorial e Revista Brasileira de Cancerologia"

*Nota do editor: reprodução na íntegra do documento Nomenclatura brasileira para laudos cervicais e condutas preconizadas - recomendaçôes para profissionais de saúde 2006, publicado por Brasil. Ministério da Saúde / Secretaria de Atenção à Saúde / Instituto Nacional de Câncer / Coordenação de Prevenção e Vigilância, ISBN 85-7318-109-5. 


\section{INTRODUÇÃO}

O câncer do colo do útero é um grande problema de Saúde Pública no Brasil e no mundo.

As mais altas taxas de incidência do câncer do colo do útero são observadas em países pouco desenvolvidos, indicando uma forte associação desse tipo de câncer com as condiçōes de vida precária, com os baixos índices de desenvolvimento humano, com a ausência ou fragilidade das estratégias de educação comunitária (promoção e prevenção em saúde) e com a dificuldade de acesso a serviços públicos de saúde para o diagnóstico precoce e o tratamento das lesões precursoras. Esta situação torna indispensáveis políticas de saúde pública bem estruturadas.

Nos países desenvolvidos, a sobrevida média estimada em cinco anos varia de 59\% a 69\%. Nos países em desenvolvimento, os casos são encontrados em estágios relativamente avançados e, conseqüentemente, a sobrevida média é estimada em $49 \%$ após cinco anos.

O Inquérito Domiciliar, realizado pelo Ministério da Saúde em 2002-2003, mostrou que, para as 15 capitais analisadas e o Distrito Federal, a cobertura estimada do exame Papanicolaou variou de $74 \%$ a $93 \%$. Entretanto, o percentual de realização desse exame pelo SUS variou de $33 \%$ a $64 \%$ do total, o que, em parte, explica o diagnóstico tardio e a manutenção das taxas de mortalidade, bem como as altas taxas de incidência observadas no Brasil. ${ }^{2}$

Ainda como reflexo deste quadro adverso, dados da Pesquisa Nacional por Amostra de Domicílio (PNAD), Saúde 2003, divulgados pelo Instituto Brasileiro de Geografia e Estatística (IBGE) em 2005, mostraram que, nos últimos três anos, a cobertura do exame citológico do colo do útero foi de $68,7 \%$ em mulheres acima de 24 anos de idade, sendo que $20,8 \%$ das mulheres nesta faixa etária nunca tinham sido submetidas ao exame preventivo $^{3}$. Como a pesquisa se baseia na informação concedida pela própria entrevistada, pode-se admitir que parte dessas mulheres, segundo certas condições socioeconômicas, possa confundir a realização de um exame ginecológico com a coleta de material cérvicouterino para exame laboratorial.

Embora o aumento de acesso ao exame preventivo tenha aumentado no país, isto não foi suficiente para reduzir a tendência de mortalidade por câncer do colo do útero e, em muitas regiōes, o diagnóstico ainda é feito em estádios mais avançados da doença. O diagnóstico tardio pode estar relacionado com: (1) a dificuldade de acesso da população feminina aos serviços e programas de saúde; (2) a baixa capacitação dos recursos humanos envolvidos na atenção oncológica (principalmente em municípios de pequeno e médio porte); (3) a capacidade do Sistema Público de Saúde para absorver a demanda que chega às unidades de saúde e (4) as dificuldades dos gestores municipais e estaduais em definir e estabelecer um fluxo assistencial, orientado por critérios de hierarquização dos diferentes níveis de atenção, que permita o manejo e o encaminhamento adequado de casos suspeitos para investigação em outros níveis do sistema.

A articulação de ações dirigidas ao câncer da mama e do colo do útero está fundamentada na Política Nacional de Atenção Oncológica (Portaria GM no 2439 de 08/12/ 2005) e no Plano de Ação para o Controle dos Cânceres de Colo do Útero e da Mama 2005-2007. Essa articulação trata das seguintes diretrizes estratégicas, compostas por ações a serem desenvolvidas, nos distintos níveis de atenção à saúde: Aumento da cobertura da populaçãoalvo; Garantia da qualidade; Fortalecimento do sistema de informação; Desenvolvimento de capacitações; Desenvolvimento de pesquisas e mobilização social.

A publicação denominada Nomenclatura Brasileira para Laudos Cervicais e Condutas Preconizadas foi elaborada com a finalidade de orientar a atenção às mulheres, subsidiando tecnicamente os profissionais de saúde, disponibilizando conhecimentos atualizados de maneira sintética e acessível que possibilitem orientar condutas adequadas em relação ao controle do câncer do colo do útero.

Os gestores municipais e estaduais são os principais parceiros no desenvolvimento das ações contidas na Nomenclatura Brasileira para Laudos Cervicais e Condutas Preconizadas. Para tanto, necessitarão de apoio na organização da rede para a atenção oncológica, na estruturação de serviços e na sistematização, quando necessário, do processo de referência e contra-referência entre os níveis de atenção.

Reforça-se, então, a participação estratégica do INCA, assessorando tecnicamente estados e municípios, além da parceria na construção de uma rede de educação permanente na atenção oncológica.

$\mathrm{Na}$ estruturação e organização da Nomenclatura Brasileira para Laudos Cervicais e Condutas Preconizadas, foram preservados conceitos consensuais com descrição minuciosa. Em um formato mais específico, os diversos capítulos, abaixo sumarizados, sugerem orientações às ações a serem desenvolvidas a partir do ano de 2006, nos distintos níveis de atenção à saúde no âmbito do SUS.

Para que as estratégias, normas e procedimentos que orientam as ações de controle do câncer do colo do útero, no país, estejam em consonância com o conhecimento 
científico atual, o Ministério da Saúde tem realizado parcerias com sociedades científicas e considerado a opinião de especialistas nacionais e internacionais. Finalizando o processo de trabalho, o Ministério da Saúde, por meio da Área Técnica da Saúde da Mulher e do Instituto Nacional de Câncer, submeteu à consulta pública o referido documento. Na Metodologia de Trabalho são apresentadas todas as etapas do trabalho realizadas ao longo dos anos.

O capítulo que trata da Nomenclatura Brasileira para Laudos Citopatológicos contempla aspecto de atualidade tecnológica, e sua similaridade com o Sistema Bethesda $2001^{4}$ facilita a equiparação dos resultados nacionais com aqueles encontrados nas publicações científicas internacionais. São introduzidos novos conceitos estruturais e morfológicos, o que contribui para o melhor desempenho laboratorial e serve como facilitador da relação entre a citologia e a clínica. Sua estrutura geral facilita a informatização dos laudos, o que permite o monitoramento da qualidade dos exames citopatológicos realizados no SUS. Além disso, a anuência das sociedades científicas envolvidas com a confirmação diagnóstica e o tratamento das lesões torna possível o estabelecimento de diretrizes para as condutas terapêuticas.

Em Avaliação pré-analítica e Adequabilidade da amostra, destaca-se a introdução dos conceitos de Avaliação préanalítica e conduta, em que a adequabilidade da amostra passará à classificação binária (satisfatória ou insatisfatória). Destaca-se ainda a recomendação nacional para o exame citopatológico cervical o qual deverá ser realizado em mulheres de 25 a 60 anos de idade, ou que já tiveram atividade sexual anteriormente a esta faixa etária, uma vez por ano e, após dois exames anuais consecutivos negativos, a cada três anos.

Em Condutas preconizadas, tanto para resultado normal, alteraçôes benignas e queixas ginecológicas como para Alteraçōes pré-malignas ou malignas no exame citopatológico, encontra-se o desenho dos possíveis achados e das possibilidades de encaminhamentos, nos diferentes níveis de complexidade. O objetivo é auxiliar os profissionais de saúde, gerentes e gestores nas condutas a serem aplicadas e nas ações de organização de rede.

Para o acompanhamento e a avaliação do impacto da implantação da Nomenclatura Brasileira para Laudos Cervicais e Condutas Preconizadas, é necessário um Sistema de Informação que permita monitorar o processo de rastreamento, o diagnóstico, o tratamento e a qualidade dos exames realizados na rede SUS. Para tanto, houve o aprimoramento do Sistema Nacional de Informação do Câncer do Colo do Útero (SISCOLO), tanto na vertente tecnológica como em decorrência da implantação da
Nomenclatura Brasileira para Laudos Cervicais.

Atualmente, o SISCOLO ainda não permite a identificação do número de mulheres examinadas, mas apenas a quantidade de exames realizados, dificultando o conhecimento preciso das taxas de captação e cobertura, essenciais ao acompanhamento das ações planejadas. Portanto, é indispensável o desenvolvimento de estratégias para estimular/induzir estados e municípios quanto ao registro do número do cartão SUS. É importante também melhorar o sistema de forma a desencadear o "módulo seguimento" do SISCOLO, o qual permitirá o acompanhamento das mulheres com exames alterados desde a sua entrada no sistema, através da coleta do exame até o seu desfecho, tratamento/ cura.

Por fim, deve-se considerar o estímulo ao desenvolvimento de pesquisas na linha de prevenção e controle do câncer do colo do útero, uma vez que essas contribuem para a melhoria da efetividade, eficiência e qualidade de políticas, sistemas e programas.

\section{METODOLOGIA DE TRABALHO}

A revisão da nomenclatura foi realizada a partir de amplo debate com profissionais de saúde, gerentes, gestores das secretarias estaduais e municipais, sociedades científicas e especialistas reconhecidos nacional e internacionalmente. $\mathrm{O}$ processo de discussão teve início em 1988 e ocorreu na forma de oficinas, grupo de trabalho, aplicação das condutas preconizadas em grupo focal para avaliação qualitativa e consulta pública do documento final, pelo Ministério da Saúde, por meio da Área Técnica da Saúde da Mulher e do Instituto Nacional de Câncer (dez/2005 a jan/2006).

$\mathrm{O}$ consenso sobre a nova nomenclatura foi baseado no Sistema de Bethesda, desenvolvido no Instituto Nacional de Câncer dos Estados Unidos, atualizado em 2001 e, além da participação das áreas técnicas do Ministério da Saúde (Instituto Nacional de Câncer, Área Técnica de Saúde da Mulher, Coordenação de DST/AIDS) e de representantes das secretarias estaduais e municipais de saúde, contou com a participação da Sociedade Brasileira de Citologia (SBC), Sociedade Brasileira de Patologia (SBP), Sociedade Brasileira de Patologia do Trato Genital Inferior e Colposcopia (SBTGIC), Federação Brasileira das Associaçōes de Ginecologia e Obstetrícia (FEBRASGO), Agência Nacional de Vigilância Sanitária (ANVISA), Instituto Brasileiro de Controle do Câncer (IBCC), Instituto Fernandes Figueira (IFF/Fiocruz), Hospital do Câncer A.C. Camargo, Fundação Oncocentro de São Paulo (FOSP), Centro de Atenção Integral à Saúde da Mulher da 
Universidade Estadual de Campinas (CAISM/ UNICAMP). Esta revisão atualiza o documento anterior de normatização (Ministério da Saúde, 2003) e incorpora as recentes evidências científicas com o objetivo de qualificar as ações voltadas à atenção integral à mulher.

\section{NOMENCLATURA BRASILEIRA PARA LAUDOS CITOPATOLÓGICOS CERVICAIS}

Desde que o Dr. George Papanicolaou tentou classificar as células que observava, acreditando serem a representação de lesōes neoplásicas, ocorreram diversas modificações que incorporaram progressivamente o conhecimento adquirido sobre a história natural dessas lesões, sempre na tentativa de melhorar a correlação cito-histológica. Deve-se notar que o objetivo do teste continua o mesmo, ou seja, a intenção é identificar alterações sugestivas de uma doença e, como conseqüência, também indicar ações que permitam o diagnóstico de certeza.

Papanicolaou criou uma nomenclatura que procurava expressar se as células observadas eram normais ou não, atribuindo-lhes uma classificação. Assim, falava-se em Classes I, II, III, IV e V, em que a Classe I - indicava ausência de células atípicas ou anormais; Classe II - citologia atípica, mas sem evidência de malignidade; Classe III citologia sugestiva, mas não conclusiva de malignidade; Classe IV - citologia fortemente sugestiva de malignidade; e Classe V - citologia conclusiva de malignidade.

Se essa classificação se preocupava pouco com os aspectos histológicos das lesôes que sugeriam, a partir de então, novas nomenclaturas surgiram mais atentas a esse significado. Assim, o termo "displasia" foi introduzido na classificação, levando em conta alterações histológicas correspondentes, identificando displasias leves, moderadas e severas. Todos os graus de displasias eram grosseiramente referentes à classe III de Papanicolaou, correlacionando também a Classe IV com carcinomas escamosos in situ. A Classe $\mathrm{V}$ continuou a indicar carcinoma invasor, e, pela primeira vez, se deu ênfase a alteraçôes celulares, devido à ação do vírus do Papiloma Humano (HPV), relatando-se a coilocitose 5 .

Em uma etapa posterior, estabeleceu-se o conceito de neoplasia intra-epitelial e no caso da cérvice uterina, de neoplasia intra-epitelial cervical (NIC) subdividida em três graus, que se mantém para os diagnósticos histológicos. A classificação citológica mais atual do esfregaço cervical é o Sistema de Bethesda, Maryland, Estados Unidos. Essa classificação incorporou vários conceitos e conhecimentos adquiridos que, resumidamente, são estes: o diagnóstico citológico deve ser diferenciado para as células escamosas e glandulares; inclusão do diagnóstico citomorfológico sugestivo da infecção por HPV, devido às fortes evidências do envolvimento desse vírus na carcinogênese dessas lesōes, dividindo-as em lesōes intra-epiteliais de baixo e alto graus, ressaltando o conceito de possibilidade de evolução para neoplasia invasora; e a introdução da análise da qualidade do esfregaço. Essa classificação foi revista em 1991 e 2001, porém sem mudanças estruturais.

\subsection{TIPOS DA AMOSTRA}

\section{Citologia:}

- Convencional

- Em meio líquido

Nota explicativa: Com a recente introdução da citologia em meio líquido, em suas diferentes apresentaçōes, é indispensável que seja informada a forma de preparo, uma vez que a adequabilidade do material é avaliada de forma diversa para cada meio. É, ainda, de fundamental importância que o laboratório informe, em caso de citologia em meio líquido, qual sistema foi usado.

\subsection{Avaliação pré-analítica}

\section{Amostra rejeitada por:}

- Ausência ou erro de identificação da lâmina e/ou do frasco;

- Identificação da lâmina e/ou do frasco não coincidente com a do formulário;

- Lâmina danificada ou ausente;

- Causas alheias ao laboratório (especificar);

- Outras causas (especificar).

Nota explicativa: Este conceito foi introduzido como uma inovação, visando a estabelecer a diferença entre rejeição por causas alheias e anteriores à chegada ao laboratório e aquelas relacionadas à colheita, coloração ou análise microscópica. A causa da rejeição deverá ser identificada, de preferência, no momento da entrada da lâmina no laboratório e seu registro deverá ser feito. Contudo, é o profissional responsável pelo exame quem irá assinar o laudo contendo o motivo da rejeição.

\subsection{AdeQuabiLIDADE DA AMOSTRA}

- Satisfatória;

- Insatisfatória para avaliação oncótica devido ao:

Material acelular ou hipocelular ( $<10 \%$ do esfregaço)

Leitura prejudicada ( $>75 \%$ do esfregaço) por presença de: 
- sangue;

- piócitos;

- artefatos de dessecamento;

- contaminantes externos;

- intensa superposição celular;

- outros (especificar).

\section{Epitélios representados na Amostra:}

- Escamoso;

- Glandular;

- Metaplásico.

Nota explicativa: A questão da Adequabilidade da Amostra vem, ao longo do tempo, suscitando inúmeros questionamentos e modificações, dado o seu caráter de matéria conflitante e de difícil conceituação plenamente aceitável. A disposição, em um sistema binário (satisfatória $\mathrm{x}$ insatisfatória), melhor caracteriza a definição da visão microscópica da colheita. No atual Sistema de Bethesda (2001), a Adequabilidade da Amostra também está colocada nesses dois parâmetros. Contudo, nesse sistema, a caracterização da junção escamo-colunar faz parte dessa definição, o que não ocorre aqui. Deve-se considerar como satisfatória a amostra que apresente células em quantidade representativa, bem distribuídas, fixadas e coradas, de tal modo que sua visualização permita uma conclusão diagnóstica. Observe-se que os aspectos de representatividade não constam desse item, mas deverão constar de caixa própria, para que seja dada a informação (obrigatória) dos epitélios que estão representados na amostra. A definição de Adequabilidade pela representatividade passa a ser da exclusiva competência do responsável pela paciente, que deverá levar em consideração as condiçōes próprias de cada uma (idade, estado menstrual, limitações anatômicas, objetivo do exame etc). Insatisfatória é a amostra cuja leitura esteja prejudicada pelas razóes expostas acima, todas de natureza técnica e não de amostragem celular.

\subsection{DIAGNÓSTICO DESCRITIVO}

- Dentro dos limites da normalidade, no material examinado;

- Alterações celulares benignas;

- Atipias celulares.

Nota explicativa: $\mathrm{O}$ acréscimo da expressão "no material examinado" visa a estabelecer, de forma clara e inequívoca, o aspecto do momento do exame. Aqui, também, ocorre uma diferença importante com o Sistema Bethesda 2001, no qual foi excluída a categoria das alterações celulares benignas. Tal manutenção devese ao entendimento de que os fatores que motivaram a exclusão não se aplicam à realidade brasileira.

\subsubsection{Alterações celulares benignas}

- Inflamação

- Reparação

- Metaplasia escamosa imatura

- Atrofia com inflamação

- Radiação

- Outras (especificar)

Nota explicativa: Em relação à nomenclatura anterior, a única mudança ocorre pela introdução da palavra "imatura" em metaplasia escamosa, buscando caracterizar que é esta a apresentação que deve ser considerada como alteração. Assim sendo, a metaplasia matura, com sua diferenciação já definida, não deve ser considerada como inflamação e, eventualmente, nem necessita ser citada no laudo, exceto na indicação dos epitélios representados, para caracterizar o local de colheita.

\subsubsection{Atipias celulares}

\section{Células atípicas de significado indeterminado:}

- Escamosas:

- Possivelmente não-neoplásicas;

- Não se pode afastar lesão intra-epitelial de alto grau. - Glandulares:

- Possivelmente não-neoplásicas;

- Não se pode afastar lesão intra-epitelial de alto grau.

- De origem indefinida:

- Possivelmente não-neoplásicas;

- Não se pode afastar lesão intra-epitelial de alto grau. Nota explicativa: Esta é mais uma inovação da nomenclatura brasileira, criando-se uma categoria separada para todas as atipias de significado indeterminado e, mais ainda, a categoria "de origem indefinida" destinada àquelas situações em que não se pode estabelecer com clareza a origem da célula atípica. Deve-se observar que foi excluída a expressão "provavelmente reativa", a qual foi substituída pela "possivelmente não-neoplásicas", e introduzida a expressão "não se pode afastar lesão intra-epitelial de alto grau". Com isso, pretende-se dar ênfase ao achado de lesões de natureza neoplásica, diminuindo assim o diagnóstico dúbio. Objetiva-se identificar as células imaturas, pequenas e que, por sua própria indiferenciação, podem representar maior risco de 
corresponder a lesões de alto grau. Sempre que o caso exigir, notas explicativas devem ser acrescentadas, visando a orientar o responsável pela paciente nos procedimentos adotados. Deve-se observar a exclusão total dos acrônimos (ASCUS e AGUS), cujo uso é desaconselhado, devendo sempre constar por extenso os diagnósticos.

\section{Em células escamosas:}

- Lesão intra-epitelial de baixo grau (compreendendo efeito citopático pelo HPV e neoplasia intra-epitelial cervical grau I);

- Lesão intra-epitelial de alto grau (compreendendo neoplasias intra-epiteliais cervicais graus II e III);

- Lesão intra-epitelial de alto grau, não podendo excluir microinvasão;

- Carcinoma epidermóide invasor.

Nota explicativa: Foi adotada a terminologia lesão intraepitelial em substituição ao termo neoplasia, além de estabelecer dois níveis (baixo e alto graus), separando as lesões com potencial morfológico de progressão para neoplasia daquelas mais relacionadas com o efeito citopático viral, com potencial regressivo ou de persistência. Foi ainda incluída a possibilidade diagnóstica de suspeição de microinvasão. Recomendase enfaticamente que seja evitado o uso de outras nomenclaturas e classificações, além das aqui já contempladas, evitando-se a perpetuação de termos eventualmente já abolidos ou em desuso, os quais nada contribuem para o esclarecimento diagnóstico.

\section{Em células glandulares:}

- Adenocarcinoma in situ;

- Adenocarcinoma invasor: Cervical;

Endometrial;

Sem outras especificações.

- Outras neoplasias malignas;

- Presença de células endometriais (na pós-menopausa ou acima de 40 anos, fora do período menstrual).

Nota explicativa: A introdução da categoria Adenocarcinoma in situ reconhece a capacidade de identificação morfológica desta entidade e acompanha a nomenclatura internacional. $\mathrm{O}$ item "sem outras especificações" refere-se exclusivamente a adenocarcinomas de origem uterina. Quando for identificada neoplasia de origem glandular extra-uterina, deve ser colocada no quadro das outras neoplasias malignas, especificando o tipo, em nota complementar. As células endometriais somente necessitam ser mencionadas quando a sua presença possa ter significado patológico. Assim sendo, seu achado nos primeiros doze dias que sucedem ao período menstrual, apenas deverá ser referido se houver importância para a identificação de algum processo patológico.

\subsection{Microbiologia}

- Lactobacillus sp;

- Bacilos supracitoplasmáticos (sugestivos de Gardnerellal

Mobiluncus);

- Outros bacilos;

- Cocos;

- Candida sp;

- Trichomonas vaginalis;

- Sugestivo de Chlamydia sp;

- Actinomyces sp;

- Efeito citopático compatível com vírus do grupo Herpes;

- Outros (especificar).

Nota explicativa: Foram mantidas as informações de Chlamydia, cocos e bacilos por considerar-se a oportunidade, por vezes única, em um país continental e com grandes dificuldades geográficas e econômicas, de estabelecer uma terapêutica antimicrobiana baseada exclusivamente no exame preventivo. A introdução da expressão "Bacilos supracitoplasmáticos" busca indicar a apresentação morfológica de agentes microbianos de difícil distinção pelo exame corado e fixado pela técnica citológica, mas que, de modo geral, respondem aos mesmos tratamentos.

\section{AVALIAÇÃO PRÉ-ANALÍTICA E ADEQUABILIDADE DA AMOSTRA}

\subsection{LAUdO CITOPATOLÓGICO}

A nomenclatura brasileira utilizada para laudos citopatológicos tem sofrido constantes alteraçóes. A adoção do Sistema de Bethesda, ainda que adaptado ao Brasil, facilita a comparação de resultados nacionais com os encontrados em publicaçóes estrangeiras. É importante ressaltar que a introdução de novos conceitos estruturais e morfológicos contribui, tanto para o desempenho do laboratório quanto para a relação entre a citologia e a clínica.

Sabe-se, no entanto, que essas mudanças ocorrem de forma gradual e, basicamente, dependem da adoção da nova terminologia na rotina diária dos profissionais de saúde, fonte de alimentação de conhecimento para a mídia escrita ou falada e para a população em geral.

Atualmente, não é razoável que alguns laboratórios ainda emitam laudos de citopatologia somente com a nomenclatura ultrapassada, uma vez que a proposta de novas categorias de resultados impede que se estabeleça 
correlação pertinente entre Bethesda 2001 e Papanicolaou.

Em contrapartida, também é conveniente que médicos, ginecologistas ou não, ao receberem os resultados de exames, compreendam o diagnóstico. Portanto, pretende-se explicar aqui o significado deles, com vistas a uniformizar o uso da nomenclatura no Brasil, estabelecida por consenso entre experts no assunto.

A seguir, será apresentada a possibilidade de associação de todos os resultados possíveis nos laudos dos exames e as respectivas condutas clínicas.

\subsection{NOMENCLATURA BRASILEIRA}

\subsubsection{Avaliação pré-analítica (que ocorre antes da análise microscópica da lâmina)}

Este conceito foi introduzido como uma inovação, visando a estabelecer a diferença entre a rejeição da lâmina por causas anteriores à sua entrada no laboratório de citopatologia e aquelas relacionadas à técnica de coleta, coloração ou análise microscópica. A causa da rejeição deverá ser identificada no momento da entrada da lâmina no laboratório e de seu registro. O profissional responsável pelo registro é quem irá apontar o motivo da rejeição.

\section{Amostra rejeitada:}

- Ausência ou erro de identificação da lâmina;

- Identificação da lâmina não coincidente com a do formulário;

- Lâmina danificada ou ausente.

Conduta Clínica: A paciente deverá ser convocada para repetir o exame, devendo ser explicado à mesma que o motivo é técnico e não por alteração patológica.

\subsubsection{Adequabilidade da amostra}

$\mathrm{Na}$ atual nomenclatura utilizada para definir a Adequabilidade da Amostra, estabelece-se o sistema binário: satisfatório e insatisfatório. Portanto, o termo anteriormente utilizado "satisfatório mas limitado" foi abolido.

\section{Insatisfatória para Avaliação}

É considerada insatisfatória a amostra cuja leitura esteja prejudicada pelas razóes expostas abaixo, algumas de natureza técnica e outras de amostragem celular, podendo ser assim classificada:

- Material acelular ou hipocelular ( $<10 \%$ do esfregaço);

- Leitura prejudicada ( $>75 \%$ do esfregaço) por presença de: sangue; piócitos;

artefatos de dessecamento;

contaminantes externos;

intensa superposição celular.

Conduta Clínica: A paciente deverá ser convocada para repetir o exame de imediato, devendo ser explicado à mesma que o motivo é técnico e não por alteração patológica.

\section{Satisfatória}

Designa amostra que apresente células em quantidade representativa, bem distribuídas, fixadas e coradas, de tal modo que sua visualização permita uma conclusão diagnóstica.

\section{Epitélios Representados na Amostra:}

- Escamoso;

- Glandular (não inclui o epitélio endometrial);

- Metaplásico.

Embora a indicação dos epitélios representados na amostra seja informação obrigatória nos laudos citopatológicos, seu significado deixa de pertencer à esfera de responsabilidade dos profissionais que realizam a leitura do exame. Agora, eles respondem apenas pela indicação dos epitélios que estão representados. Todavia, deve-se alertar que a amostra adequada pode não ter a representação completa da junção escamo-colunar, o que deverá ser avaliado pelo ginecologista.

A presença de células metaplásicas ou células endocervicais, representativas da junção escamo-colunar (JEC), tem sido considerada como indicador da qualidade do exame, pelo fato de as mesmas se originarem do local onde se situa a quase totalidade dos cânceres do colo do útero.

A presença exclusiva de células escamosas deve ser avaliada pelo médico responsável. É muito oportuno que os profissionais de saúde atentem para a representatividade da JEC nos esfregaços cérvicovaginais, sob pena de não propiciar à mulher todos os benefícios da prevenção do câncer do colo do útero.

\subsubsection{Periodicidade de realização do exame citopatológico*}

A realização do exame citopatológico de Papanicolaou tem sido reconhecida mundialmente como uma estratégia segura e eficiente para a detecção precoce do câncer do colo do útero na população feminina e tem modificado efetivamente as taxas de incidência e mortalidade por este câncer.

\footnotetext{
* Texto publicado na Revista Brasileira de Cancerologia no 48, vol.1, 2002 (Periodicidade de realização do exame preventivo do câncer do colo do útero: normas e recomendaçôes do INCA). ${ }^{6}$
} 
A efetividade da detecção precoce do câncer do colo do útero por meio do exame de Papanicolaou, associada ao tratamento desse câncer em seus estádios iniciais, tem resultado em uma redução das taxas de incidência de câncer cervical invasor que pode chegar a $90 \%$, quando o rastreamento apresenta boa cobertura (80\%, segundo a Organização Mundial da Saúde OMS) e é realizado dentro dos padrōes de qualidade (Gustafsson et al., 1997).

Em 1988, o Ministério da Saúde, por meio do Instituto Nacional de Câncer, realizou uma reunião de consenso, com a participação de diversos experts internacionais, representantes das sociedades científicas e das diversas instâncias ministeriais e definiu que, no Brasil, o exame colpocitopatológico deveria ser realizado em mulheres de 25 a 60 anos de idade, uma vez por ano e, após dois exames anuais consecutivos negativos, a cada três anos.

Tal recomendação apóia-se na observação da história natural do câncer do colo do útero, que permite a detecção precoce de lesôes pré-neoplásicas e o seu tratamento oportuno, graças à lenta progressão que apresenta para doença mais grave.

O câncer do colo do útero inicia-se a partir de uma lesão pré-invasiva, curável em até $100 \%$ dos casos (anormalidades epiteliais conhecidas como displasia e carcinoma in situ ou diferentes graus de neoplasia intra-epitelial cervical NIC), que normalmente progride lentamente, por anos, antes de atingir o estágio invasor da doença, quando a cura se torna mais difícil, quando não impossível.

Barron e Richart (1968) mostraram que, na ausência de tratamento, o tempo mediano entre a deteç̧ão de uma displasia leve (HPV, NIC I) e o desenvolvimento de carcinoma in situ é de 58 meses, enquanto para as displasias moderadas (NIC II) esse tempo é de 38 meses e, nas displasias graves (NIC III), de 12 meses. Em geral, estima-se que a maioria das lesões de baixo grau regredirão espontaneamente, enquanto cerca de $40 \%$ das lesões de alto grau não tratadas evoluirão para câncer invasor em um período médio de dez anos (Sawaya et al., 2001). Por outro lado, o Instituto Nacional de Câncer dos Estados Unidos (NCI, 2000) calcula que somente $10 \%$ dos casos de carcinoma in situ evoluirão para câncer invasor no primeiro ano, enquanto $30 \mathrm{a}$ $70 \%$ terão evoluído decorridos dez a 12 anos, caso não seja oferecido tratamento.

Segundo a OMS, estudos quantitativos têm demonstrado que, nas mulheres entre 35 e 64 anos, depois de um exame citopatológico do colo do útero negativo, um exame subseqüente pode ser realizado a cada três anos, com a mesma eficácia da realização anual. Conforme apresentado na tabela abaixo, a expectativa de redução percentual no risco cumulativo de desenvolver câncer, após um resultado negativo, é praticamente a mesma, quando o exame é realizado anualmente (redução de $93 \%$ do risco) ou quando ele é realizado a cada três anos (redução de $91 \%$ do risco).

Tabela 1. Efeito protetor do rastreamento para câncer do colo do útero de acordo com o intervalo entre os exames em mulheres de 35 a 64 anos

\begin{tabular}{c|c}
\hline $\begin{array}{c}\text { Intervalo entre os } \\
\text { exames }\end{array}$ & Redução na incidência cumulativa \\
\hline 1 ano & $93 \%$ \\
\hline 2 anos & $93 \%$ \\
\hline 3 anos & $91 \%$ \\
\hline 5 anos & $84 \%$ \\
\hline 10 anos & $64 \%$ \\
\hline
\end{tabular}

Fonte: van Oortmarssen et al., 1992 In: Instituto Nacional de Câncer; 2002

A experiência internacional tem mostrado uma importante redução nas taxas de incidência ajustadas pela população mundial, tal como apresentado na Tabela 2.

Tabela 2: Redução nas taxas de incidência do câncer do colo do útero em programas de rastreamento em países nórdicos

\begin{tabular}{c|c}
\hline Países Nórdicos & $\begin{array}{c}\text { Redução nas taxas de incidência* } \\
\text { entre 1986 e 1995 }\end{array}$ \\
\hline Islândia & $67 \%$ \\
\hline Finlândia & $75 \%$ \\
\hline Suécia & $55 \%$ \\
\hline Dinamarca & $54 \%$ \\
\hline Noruega & $34 \%$
\end{tabular}

* Taxas de incidência ajustadas pela população mundial

Fonte: European Commission Europe Against Cancer, 2000. In: Instituto Nacional de Câncer; 2002

Com base nas evidências científicas disponíveis, a maioria dos países europeus e organismos norteamericanos vêm recomendando a realização do exame citopatológico do colo do útero, a cada três anos.

A periodicidade de realização do exame citopatológico do colo do útero, estabelecida pelo Ministério da Saúde do Brasil, em 1988, permanece atual e está em acordo com as recomendaçôes dos principais programas internacionais. 


\section{CONDUTAS PRECONIZADAS}

\subsection{RESULTADO NORMAL, ALTERAÇÕES BENIGNAS E QUEIXAS GINECOLÓGICAS}

\subsubsection{Dentro dos limites da normalidade no material examinado}

Diagnóstico completamente normal. A inclusão da expressão "no material examinado" visa a estabelecer, de forma clara e inequívoca, aspectos do material submetido ao exame.

Conduta Clínica: Seguir a rotina de rastreamento citológico.

\subsubsection{Alterações celulares benignas (ativas ou reparativas) Inflamação sem identificação de agente}

Caracterizada pela presença de alteraçôes celulares epiteliais, geralmente determinadas pela ação de agentes físicos, os quais podem ser radioativos, mecânicos ou térmicos e químicos como medicamentos abrasivos ou cáusticos, quimioterápicos e acidez vaginal sobre o epitélio glandular. Ocasionalmente, podem-se observar alteraçōes, em decorrência do uso do dispositivo intra-uterino (DIU), em células endometriais. Casos especiais do tipo exsudato linfocitário ou reações alérgicas, representadas pela presença de eosinófilos, são observados.

Conduta Clínica: Havendo queixa clínica de leucorréia, a paciente deverá ser encaminhada para exame ginecológico. Os achados comuns são ectopias, vaginites e cervicites. O tratamento deve seguir recomendação específica.

Seguir a rotina de rastreamento citológico, independentemente do exame ginecológico.

\section{Resultado indicando Metaplasia Escamosa Imatura}

A palavra "imatura", em metaplasia escamosa, foi incluída na Nomenclatura Brasileira buscando caracterizar que esta apresentação é considerada como do tipo inflamatório, entretanto, o epitélio nessa fase está vulnerável à ação de agentes microbianos e em especial do HPV.

Conduta Clínica: Seguir a rotina de rastreamento citológico.

\section{Resultado indicando Reparação}

Decorre de lesôes da mucosa com exposição do estroma e pode ser determinado por quaisquer dos agentes que determinam inflamação. É, geralmente, a fase final do processo inflamatório, momento em que o epitélio está vulnerável à ação de agentes microbianos e em especial do HPV.

Conduta Clínica: Seguir a rotina de rastreamento citológico.
Resultado indicando atrofia com inflamação

Conduta Clínica: Após avaliação da sintomatologia e do exame ginecológico, podem ser utilizados cremes vaginais contendo estrogênios.

Seguir a rotina de rastreamento citológico.

\section{Resultado indicando radiação}

Nos casos de Câncer do Colo do Útero, o exame citopatológico deve ser realizado para controle de possível persistência de neoplasia residual ou de recidiva da neoplasia após tratamento radioterápico.

Conduta Clínica: Nos casos em que a citopatologia diagnosticar lesão intra-epitelial (LIE), previsível após tratamento radioterápico, a conduta deverá ser a mesma indicada para lesão intra-epitelial em pacientes submetidas a esse tratamento, devendo ser seguida de acordo com o grau da LIE.

Ressaltamos a importância do preenchimento completo e adequado dos dados de anamnese constantes do formulário de "Requisição de Exame Citopatológico - Colo do Útero".

\section{Achados Microbiológicos:}

- Lactobacillus sp;

- Cocos;

- Outros Bacilos.

São considerados achados normais. Fazem parte da flora vaginal e não caracterizam infecções que necessitem de tratamento.

Conduta Clínica: A paciente com sintomatologia deve ser encaminhada para avaliação ginecológica.

Seguir a rotina de rastreamento citológico.

\section{Queixas Ginecológicas}

As queixas ginecológicas não só devem ser valorizadas, mas solucionadas, considerando que os laudos do exame citológico, na maioria das vezes, mencionam agentes microbiológicos que, quando associados às queixas clínicas, merecem tratamento específico.

\subsection{Alterações Pré-malignas ou malignas nO exame CITOPATOLÓGICO}

A discussão das condutas preconizadas, apresentadas a seguir, foi baseada, principalmente, no Consensus Guidelines for the Management of Women with Cervical Cytological Abnormalities (2001)7, embora inúmeros trabalhos científicos tenham sido consultados pelos grupos de trabalho. 


\subsubsection{Células escamosas atípicas de significado indeterminado}

Atualmente, as atipias escamosas de significado indeterminado representam a atipia citológica mais comumente descrita nos resultados dos laudos citopatológicos do colo do útero. Este achado citológico é de difícil reprodutibilidade entre citopatologistas experientes e são consideradas aceitáveis taxas inferiores a $5 \%$ do total de exames realizados 8 .

A repetição do exame citopatológico possui sensibilidade entre 67 e $85 \% \%^{9-13}$. Não existem dados suficientes para definir o número e o intervalo entre as repetiçōes das citologias, sendo definido pelo grupo de trabalho o intervalo de seis meses.

As atipias escamosas de significado indeterminado foram divididas em: alteraçôes escamosas atípicas de significado indeterminado possivelmente não-neoplásicas (ASC-US de Bethesda) e em alterações escamosas atípicas de significado indeterminado em que não se pode afastar lesão de alto grau (ASC-H - Bethesda) ${ }^{4}$.

\subsubsection{Células escamosas atípicas de significado indeterminado, possivelmente não-neoplásicas}

Cerca de 5 a $17 \%$ das mulheres com esta atipia apresentam diagnóstico de neoplasia intra-epitelial II e $\mathrm{III}^{8,9,14}$ e 0,1 a $0,2 \%$ de carcinoma invasor no exame histopatológico, demonstrando assim baixo risco de lesōes mais avançadas ${ }^{15,16}$.

A colposcopia apresenta alta sensibilidade (96\%) e baixa especificidade ( $48 \%$ ), as quais causam alta taxa de sobrediagnóstico e de sobretratamento. Estudos têm mostrado desaparecimento dessas alteraçôes (células escamosas atípicas de significado indeterminado possivelmente não-neoplásicas) em 70 a $90 \%$ das pacientes mantidas sob observação e tratamento das infecçōes pré-existentes. ${ }^{15} \mathrm{~A}$ colposcopia é, portanto, um método desfavorável como a primeira escolha na condução das pacientes que apresentam alteraçôes escamosas atípicas de significado indeterminado possivelmente não-neoplásico. A conduta preconizada é a repetição da citologia, em seis meses, na Unidade da Atenção Básica.

Se dois exames citopatológicos subseqüentes semestrais, na Unidade da Atenção Básica, forem negativos, a paciente deverá retornar à rotina de rastreamento citológico. Porém, se o resultado de alguma citologia de repetição for sugestiva de lesão igual ou mais grave a células escamosas atípicas de significado indeterminado possivelmente não-neoplásicas, a paciente deverá ser encaminhada à Unidade de Referência de Média Complexidade para colposcopia imediata. Apresentando lesão, deve-se proceder à biopsia, e recomendação específica a partir do laudo histopatológico. Caso a colposcopia não apresente lesão, deve-se repetir a citologia em seis meses, na Unidade de Referência de Média Complexidade. Diante de duas citologias negativas consecutivas, a paciente deverá ser reencaminhada para a rotina de rastreamento citológico na Unidade da Atenção Básica. Se a citologia de repetiçâao for sugestiva de células escamosas atípicas de significado indeterminado possivelmente nãoneoplásicas, a paciente deverá ser submetida à nova colposcopia. Essa rotina deve ser mantida, até que novo achado citológico diferente de atipias de células escamosas de significado indeterminado possivelmente não-neoplásicas ou lesão colposcópica venha a aparecer. No caso de citologia de repetição positiva sugestiva de lesão mais grave, deverá ser adotada conduta específica.

As condutas recomendadas, para as pacientes com laudo citopatológico de células escamosas atípicas de significado indeterminado possivelmente nãoneoplásicas, são apresentadas na Figura 1.

\subsubsection{Células escamosas atípicas de significado indeterminado, quando não se pode excluir lesão intra-epitelial de alto grau}

Embora o diagnóstico de células escamosas atíicicas de significado indeterminado, quando não se pode excluir lesão intra-epitelial de alto grau, seja menos comum do que o de células escamosas atípicas de significado indeterminado possivelmente não-neoplásicas, o risco de lesão de alto grau (NIC II e NIC III) subjacente é alto $(24 \text { a } 94 \%)^{16,17}$. Portanto, a conduta para todas as pacientes com esse laudo, na Unidade da Atenção Básica, é a de encaminhá-las à Unidade de Referência de Média Complexidade para colposcopia imediata.

Caso a colposcopia mostre lesão, uma biopsia deve ser realizada com recomendação específica a partir do laudo histopatológico.

Não se detectando lesão à colposcopia, deve-se proceder, sempre que houver possibilidade, à revisão de lâmina:

- Revisão de lâmina, "possível e altera o laudo", a conduta a ser tomada será baseada no novo laudo.

- Revisão de lâmina, "possível, mas não altera o laudo, 


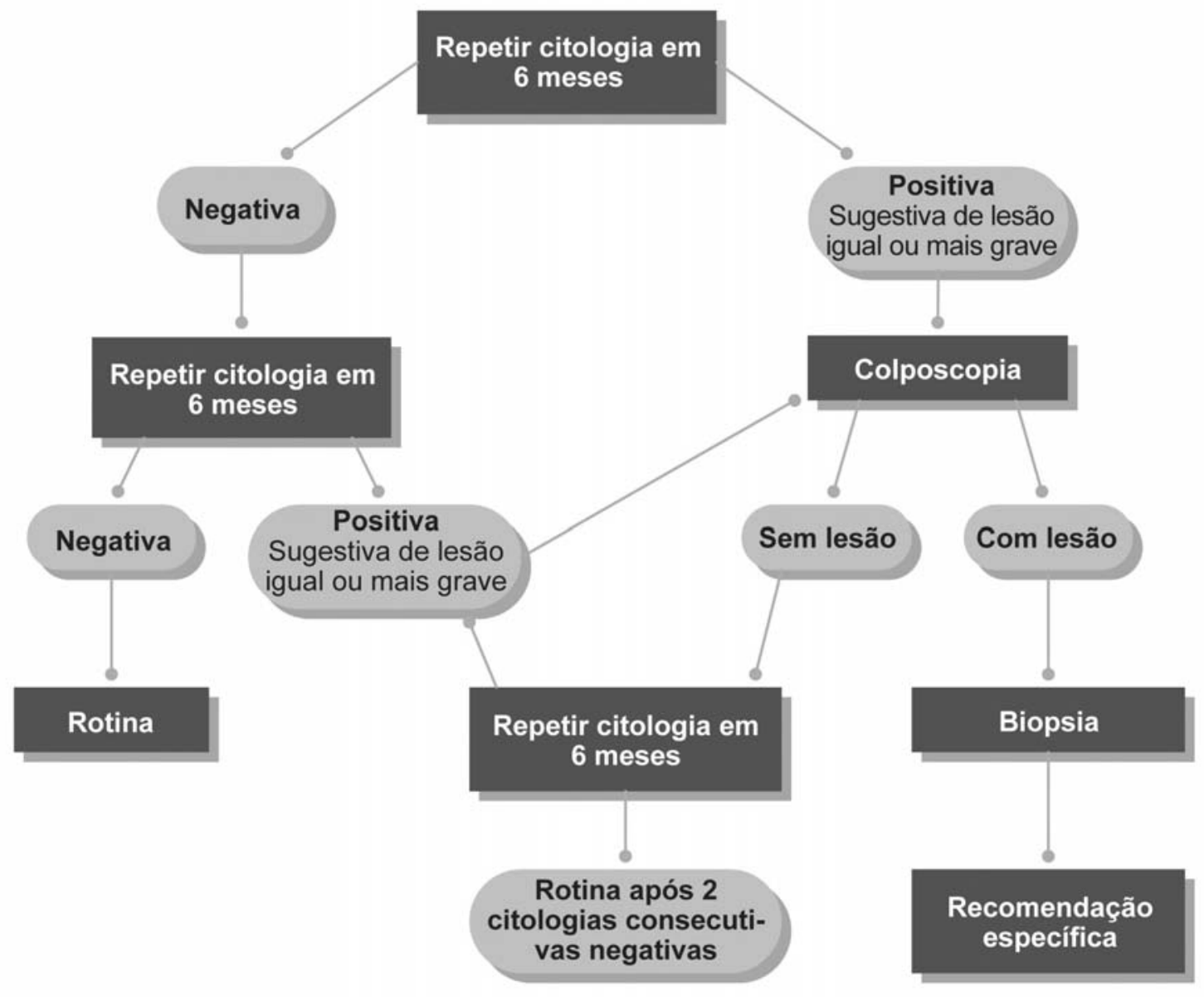

Figura 1. Recomendações para condutas frente às pacientes com células escamosas atípicas de significado indeterminado possivelmente não-neoplásicas

ou impossível", nova citologia e colposcopia devem ser realizadas em seis meses.

Duas citologias consecutivas negativas permitem que a paciente seja reencaminhada à Unidade da Atenção Básica para a rotina de rastreamento citológico. Se a citologia em seis meses for sugestiva de lesão de baixo grau ou menos grave com colposcopia negativa, deverá seguir conduta específica.

Caso o resultado citopatológico seja igual ou sugestivo de lesão mais grave com colposcopia negativa, o procedimento excisional deve ser realizado.

A biopsia se impõe, sempre que haja lesão colposcópica, independente do laudo citológico de repetição.

As condutas recomendadas, para as pacientes com células escamosas atípicas de significado indeterminado, quando não se pode excluir lesão intra-epitelial de alto grau, são apresentadas na Figura 2.

\subsubsection{Células glandulares atípicas de significado indeterminado, tanto para as possivelmente não neoplásicas quanto para aquelas em que não se pode excluir lesão intra-epitelial de alto grau}

As pacientes com atipias glandulares apresentam em 9 a $54 \%$ dos casos NIC II e III, 0 a $8 \%$ adenocarcinoma in situ e $1 \%$ a $9 \%$ adenocarcinoma invasor no exame histopatológico ${ }^{16,18-24}$. Portanto, a conduta preconizada é encaminhar a paciente à Unidade de Referência de Média Complexidade para a colposcopia imediata.

Até nova discussão, as condutas preconizadas para atipias glandulares são iguais, independente das suas subdivisões, possivelmente não-neoplásicas em que não se pode afastar lesão intra-epitelial de alto grau.

As pacientes que apresentarem lesão visível à avaliação colposcópica devem ser submetidas à biopsia e, quando esta for positiva, deverão seguir recomendação específica. No caso de resultado negativo e naquelas pacientes que não apresentem lesão visível na colposcopia, realizar-se-á coleta 


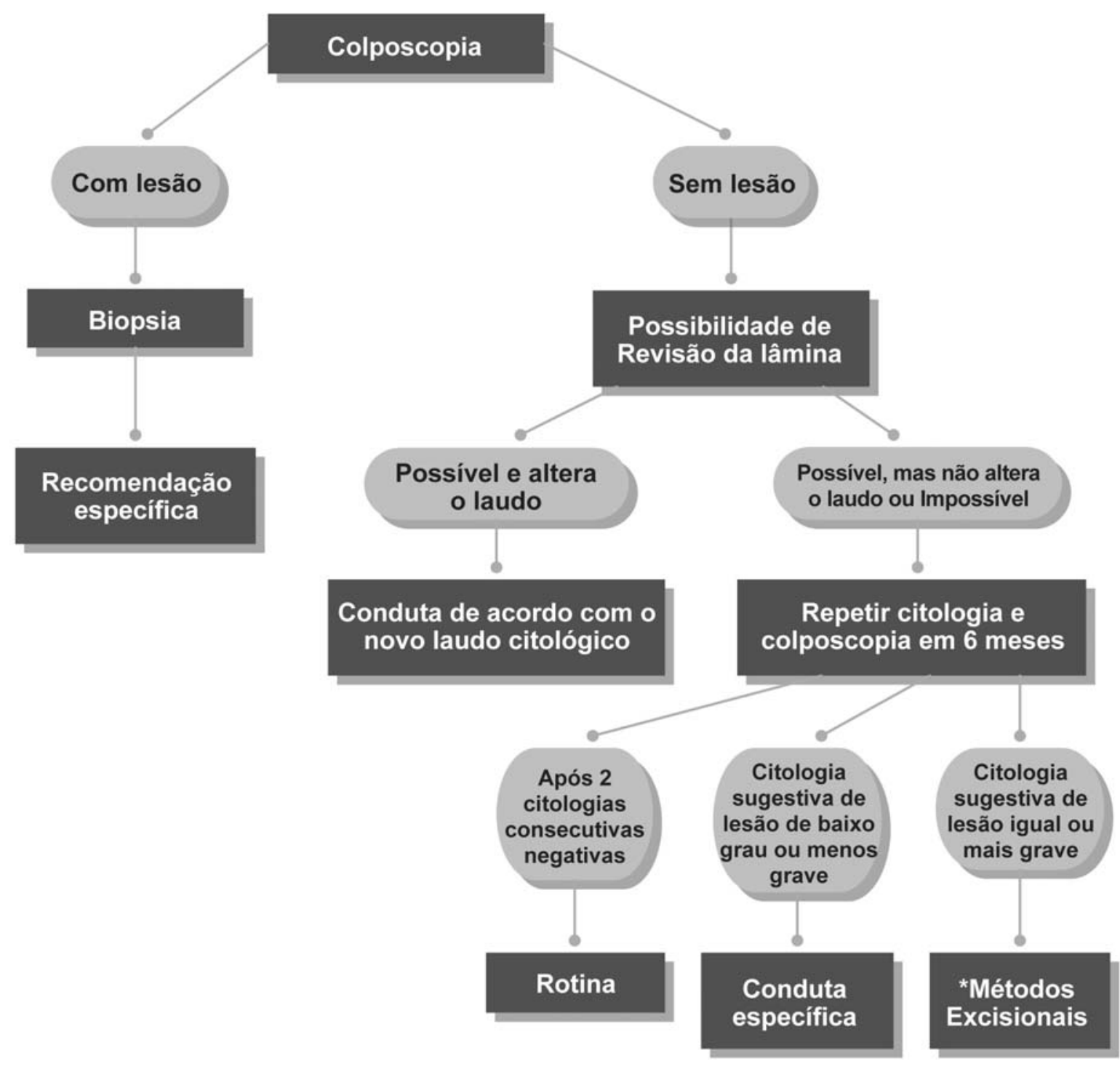

${ }^{*} \mathrm{Na}$ presença de lesão colposcópica sempre realizar biopsia.

Neste caso, o método excisional deve pressupor a retirada da Zona de Transformação e do Canal Cervical.

Figura 2. Recomendações para condutas frente às pacientes com células escamosas atípicas de significado indeterminado, quando não se pode excluir lesão intra-epitelial de alto grau

do canal cervical, imediata. O método recomendado para a coleta endocervical éo da escovinha (cytobrush), que apresenta maior sensibilidade e especificidade do que a curetagem endocervical. Além do mais, a curetagem endocervical pode ocasionar alterações no epitélio do canal cervical que dificultarão a avaliação histopatológica da peça de conização, caso esta venha a ser realizada.

A conduta subseqüente depende da avaliação do material obtido do canal cervical: se for negativo ou apresentar apenas atipias em células escamosas, as pacientes seguirão conduta específica.

Quando a avaliação do material do canal endocervical resultar em atipias em células glandulares, a conização se impõe, recomendando-se a conização a frio, até que novos trabalhos constatem a eficácia de outros procedimentos.

Deve-se recomendar investigação endometrial e anexial nas pacientes com mais de 40 anos mesmo sem irregularidade menstrual, assim como nas pacientes mais jovens com sangramento transvaginal anormal. As investigações endometrial e anexial devem ser feitas por amostragem endometrial e por exame de imagem.

As condutas recomendadas para as pacientes com laudo citopatológico de células glandulares atípicas de significado indeterminado, tanto para as possivelmente não-neoplásicas quanto para aquelas em que não se pode afastar lesão intraepitelial de alto grau, são apresentadas na Figura 3. 


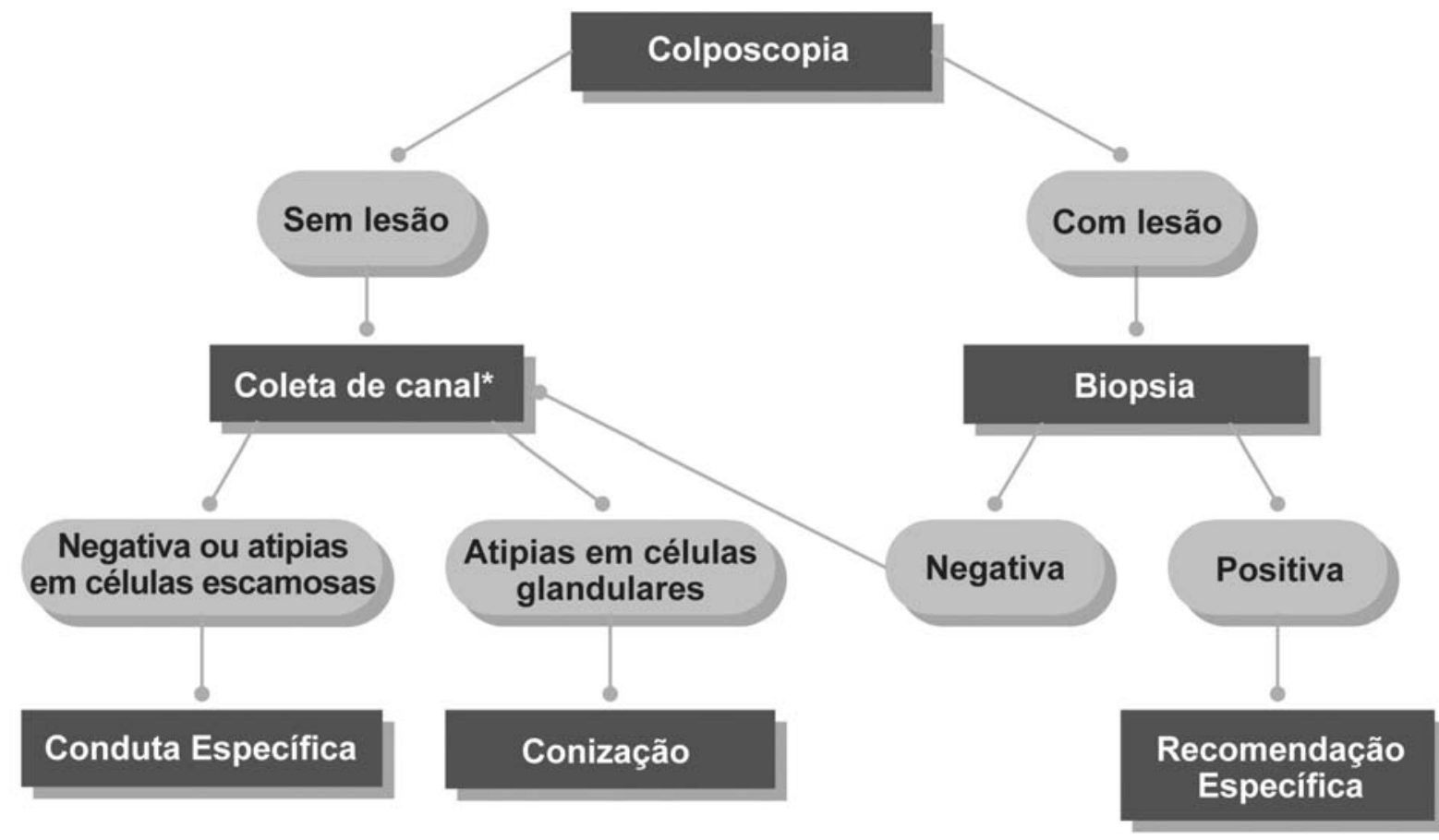

*A coleta de material do canal endocervical imediata com escova (citobrush) é a recomendada.

Nas mulheres com mais de 40 anos ou nas mais jovens com sangramento transvaginal anormal, deve-se proceder à investigação endometrial e anexial.

Figura 3. Recomendações para condutas frente às pacientes com laudo citopatológico de células glandulares atípicas de significado indeterminado

\subsubsection{Células atípicas de origem indefinida, possivelmente não-neoplásicas e que não se pode afastar lesão de alto grau}

A categoria "origem indefinida" é mais uma inovação da Nomenclatura Brasileira destinada àquelas situaçôes em que não se pode estabelecer com clareza a origem da célula atípica. Essa categoria é rara, caracterizandose como uma exceção e sua abordagem deve ser direcionada, inicialmente, ora para a conduta das células escamosas atípicas, ora para a conduta das células glandulares atípicas, de acordo com os resultados dos exames citopatológicos e colposcópicos subseqüentes.

Como a colposcopia pode ser um direcionador de condutas, tanto para as escamosas atípicas como para as glandulares atípicas, a paciente que apresentar esta alteração citopatológica na Unidade da Atenção Básica deve ser encaminhada à Unidade de Referência de Média Complexidade para colposcopia imediata.

Caso a paciente mostre lesão colposcópica, a biopsia é imperiosa. Se positiva, adotar recomendação específica. Se negativa ou a colposcopia não mostrar lesão, deverá ser realizada uma nova citologia em três meses a contar da data da última coleta.

Se o resultado da nova citologia for negativo ou sugerir atipias em células escamosas, será adotada conduta específica. Se sugerir células glandulares atípicas, a paciente deverá ser submetida à conização. Entretanto, se o resultado citopatológico mantiver laudo de células atípicas de origem indefinida, uma investigação em Centro Especializado de Alta Complexidade deve ser realizada.

Recomenda-se investigação endometrial e anexial nas pacientes com mais de 40 anos mesmo sem irregularidade menstrual, assim como nas pacientes mais jovens com sangramento transvaginal anormal, toda vez que apresentarem citologia com atipia de origem indefinida. As investigaçōes endometrial e anexial devem ser feitas por amostragem endometrial ou por exame de imagem.

As condutas recomendadas, para as pacientes com laudo citopatológico de células atípicas de origem indefinida, são apresentadas na Figura 4. 


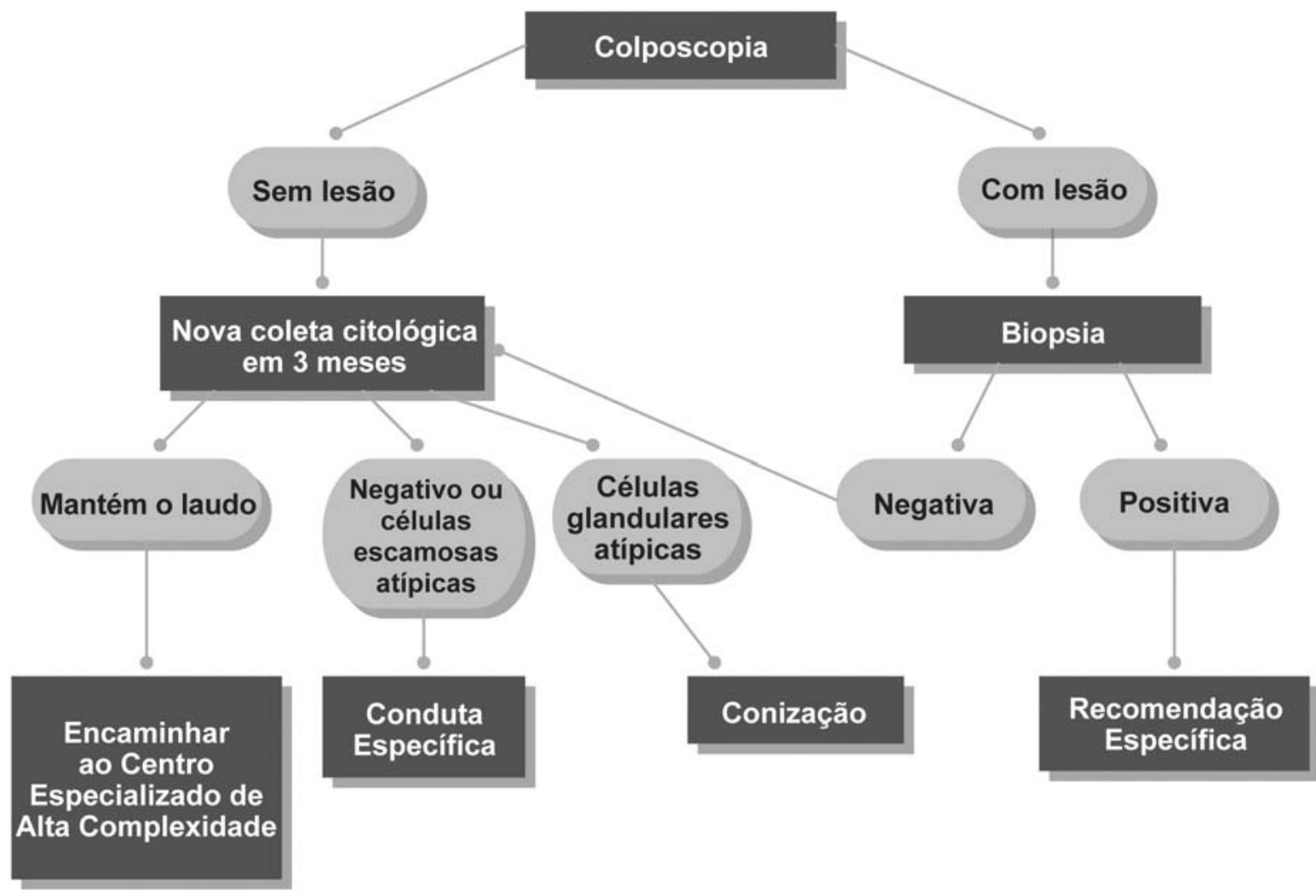

Nas mulheres com mais de 40 anos ou nas mais jovens com sangramento transvaginal anormal, deve-se proceder à investigação endometrial e anexial.

Figura 4. Recomendações para condutas frente às pacientes com laudo citopatológico de células atípicas de origem indefinida, possivelmente não-neoplásicas ou não se pode afastar lesão intra-epitelial de alto grau

\subsubsection{Lesão intra-epitelial de baixo grau}

A interpretação citológica de lesão intra-epitelial de baixo grau é mais reprodutível do que a de células escamosas atípicas de significado indeterminado possivelmente nãoneoplásica, e apresenta 15 a 30\% de chance de biopsia compatível com NIC II e NIC III ${ }^{16,17}$.

A conduta preconizada é a repetição do exame citopatológico, em seis meses, na Unidade da Atenção Básica, já que os estudos demonstram que na maioria das pacientes portadoras de lesão de baixo grau há regressão espontânea.

A colposcopia, como apresenta alta sensibilidade (96\%), baixa especificidade (48\%), alta taxa de sobrediagnóstico e de sobretratamento ${ }^{15}$, torna-se desfavorável como primeira escolha na condução das pacientes.

Se a citologia de repetição for negativa em dois exames consecutivos na Unidade da Atenção Básica, a paciente deve retornar à rotina de rastreamento citológico. Se a citologia de repetição for positiva, com qualquer atipia celular, encaminhar à Unidade de Referência de Média Complexidade para colposcopia imediata.
Se a colposcopia mostrar lesão, realizar biopsia e recomendação específica a partir do laudo histopatológico.

Se a colposcopia não mostrar lesão, a repetição da citologia em seis meses se impõe. Duas citologias consecutivas negativas permitem reencaminhar a paciente à Unidade da Atenção Básica para a rotina de rastreamento citológico.

Se algum resultado citopatológico for sugestivo de células escamosas atípicas e/ou glandulares, novamente a paciente deverá ser avaliada pela colposcopia. Se a colposcopia de repetição não mostrar lesão e a citologia de repetição mantiver laudo sugestivo de lesão de baixo grau ou de células escamosas atípicas de significado indeterminado possivelmente nãoneoplásico, a paciente deve continuar em controle citológico e colposcópico semestrais, até que o achado citopatológico diferente do anterior ou a lesão colposcópica venha a aparecer. Outros achados citopatológicos sem lesão colposcópica deverão ser conduzidos de acordo com as condutas padronizadas para cada caso.

As condutas recomendadas, para as pacientes com lesão intra-epitelial de baixo grau, são apresentadas na Figura 5. 


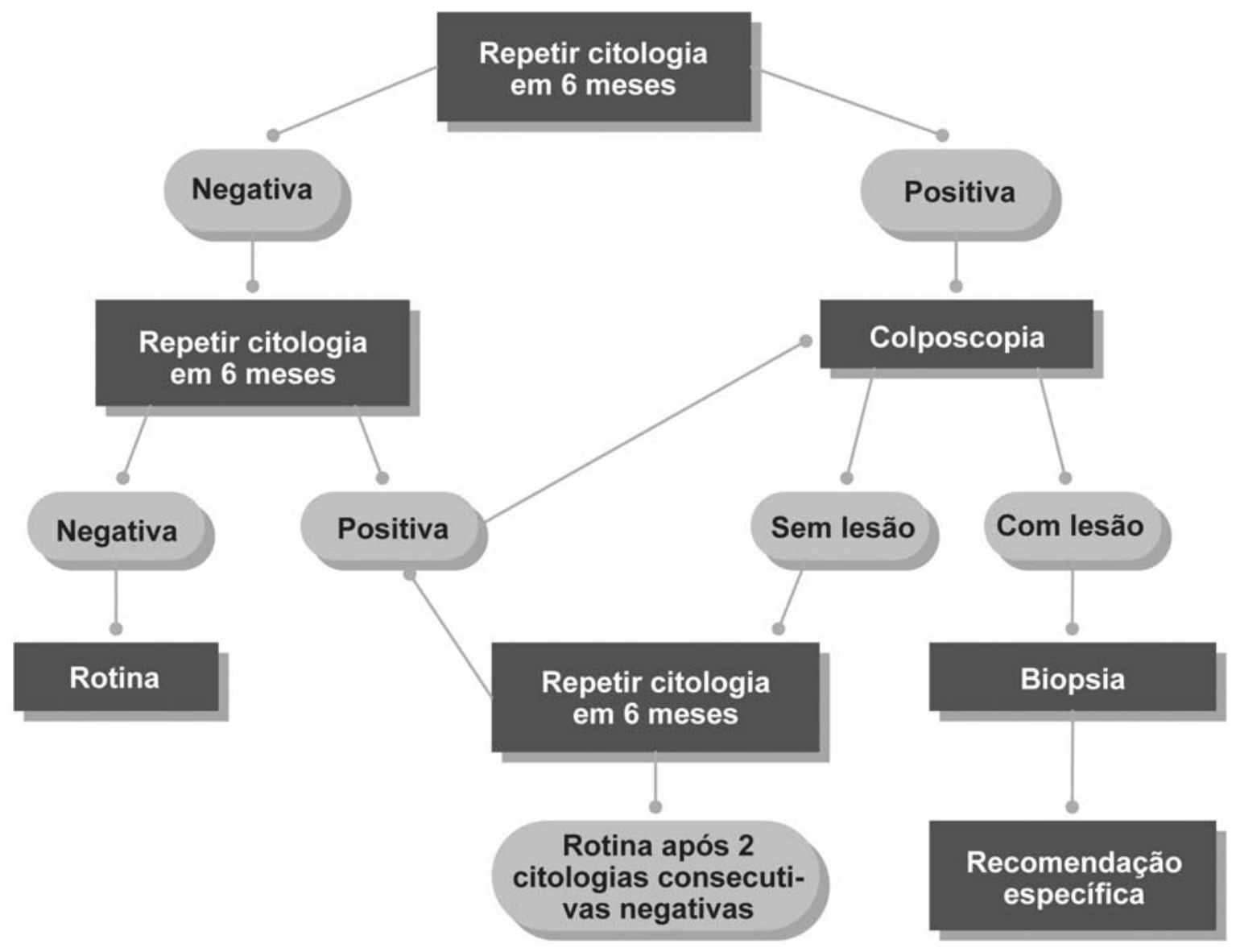

Figura 5. Recomendações para condutas frente às pacientes com lesão intra-epitelial de baixo grau

\subsubsection{Lesão intra-epitelial de alto grau}

Cerca de 70 a $75 \%$ das pacientes com laudo citológico de lesão intra-epitelial de alto grau apresentam confirmação diagnóstica histopatológica e 1 a $2 \%$ terão diagnóstico histopatológico de carcinoma invasor ${ }^{25-27}$. Sendo assim, todas as pacientes que apresentarem citologia sugestiva de lesão de alto grau, na Unidade da Atenção Básica, deverão ser encaminhadas imediatamente à Unidade de Referência de Média Complexidade para colposcopia como conduta inicial.

Quando a colposcopia for satisfatória e mostrar lesão totalmente visualizada e compatível com a citopatologia sugestiva de lesão intra-epitelial de alto grau, a conduta recomendada é a excisão ampla da zona de transformação do colo do útero, por Cirurgia de Alta Freqüência (CAF), procedimento "Ver e Tratar" que permite realizar o diagnóstico e tratamento simultâneo. Esse método elimina a necessidade de uma biopsia prévia e de consultas adicionais - pré-tratamento, já que todo o procedimento é realizado em uma única consulta.
As condições para a realização do "Ver e Tratar" são uma colposcopia satisfatória com lesão totalmente visualizada, não ultrapassando os limites do colo do útero e concordante com a citopatologia sugestiva de lesão intra-epitelial de alto grau.

Caso a colposcopia seja satisfatória e não contemple o "Ver e Tratar" ou mostre lesão não concordante com a citopatologia, uma biopsia deve ser realizada. Se a biopsia for negativa ou apresentar diagnóstico de menor gravidade, deve-se repetir a citologia em três meses a contar do dia da realização da biopsia e, adotar conduta específica de acordo com esse novo laudo citopatológico. Quando o resultado da biopsia for positivo com diagnóstico igual ou de maior gravidade, deve-se seguir recomendação específica.

Se a colposcopia for insatisfatória ou satisfatória e não mostrar nenhuma lesão, recomenda-se, sempre que houver possibilidade, a revisão de lâmina.

No caso da revisão ser possível e alterar o laudo, a conduta será baseada nesse novo laudo citopatológico. 
Porém, diante de revisão possível, mas não alterando o laudo ou impossível, uma nova citologia deve ser realizada após três meses a contar da data da coleta da citologia anterior. Se a citologia de repetição apresentar o mesmo resultado (lesão de alto grau), o procedimento excisional deve ser realizado. Se o resultado de repetição do exame citopatológico for diferente de lesão de alto grau, seguir conduta de acordo com o novo laudo.

Quando a colposcopia for insatisfatória e mostrar lesão, uma biopsia deve ser realizada. Se o resultado da biopsia for de lesão de alto grau ou de lesão de menor gravidade, a recomendação é a exerese por métodos excisionais, seja por cirurgia de alta freqüência ou conização a bisturi a frio. Se a biopsia demonstrar diagnóstico maior do que lesão de alto grau, então, a paciente deve ser referenciada para Centro Especializado de Alta Complexidade para procedimento específico.

As condutas recomendadas, para as pacientes com lesôes intra-epiteliais de alto grau, são apresentadas na Figura 6.

\subsubsection{Adenocarcinoma in situ/ invasor}

Cerca de 48 a $69 \%$ das mulheres com laudo citopatológico sugestivo de adenocarcinoma in situ apresentam confirmação da lesão à histopatologia e, dessas, 38\% apresentam laudo de adenocarcinoma invasor $^{28,29}$. Portanto, todas as pacientes com citologia sugestiva de adenocarcinoma in situ, encontradas na Unidade da Atenção Básica, deverão ser encaminhadas para a Unidade de Referência de Média Complexidade para colposcopia imediata, assim como as portadoras de laudo citopatológico sugestivo de adenocarcinoma invasor.

Se a colposcopia mostrar lesão, a biopsia deve ser realizada apenas para excluir invasão. Se o resultado histopatológico da biopsia não demonstrar lesão invasora, realizar conização. Caso seja confirmada a invasão, a paciente deve ser encaminhada para o Centro Especializado de Alta Complexidade.

Se a colposcopia não mostrar lesão, indica-se a conização, preferencialmente com bisturi a frio.

Aproximadamente $58 \%$ das pacientes com

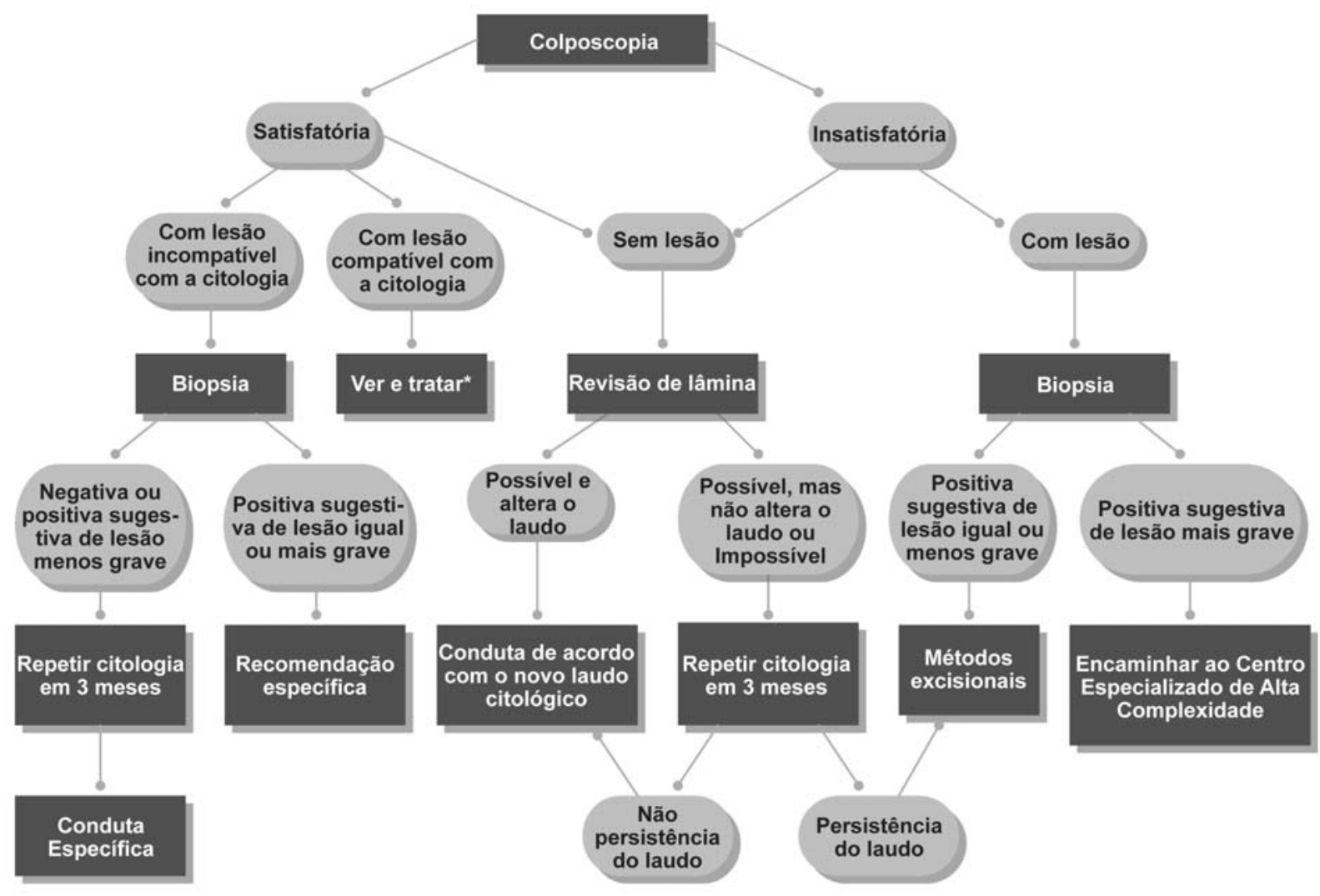

Nota Técnica: *O procedimento "Ver e Tratar" só poderá ser realizado quando a colposcopia for satisfatória, a lesão totalmente visualizada não ultrapassando os limites do colo do útero e quando houver concordância cito-colposcópica de lesão intra-epitelial de alto grau.

Figura 6. Recomendações para condutas frente às pacientes com lesão intra-epitelial de alto grau 
diagnóstico histopatológico de adenocarcinoma in situ apresentam concomitantemente lesão de alto grau ${ }^{30}$, fato que não altera a conduta a ser tomada, ou seja, mantémse a indicação da conização.

Recomenda-se a investigação endometrial e anexial nas pacientes com mais de 40 anos mesmo sem irregularidade menstrual, assim como nas pacientes mais jovens com sangramento transvaginal anormal, toda vez que apresentarem citologia com atipia glandular de significado indeterminado. As investigações endometrial e anexial devem ser feitas por amostragem endometrial ou por exame de imagem.

As recomendaçōes para as pacientes com lesōes de adenocarcinoma in situ / invasor, são apresentadas na Figura 7.

\subsubsection{Lesão de alto grau não podendo excluir microinvasão ou carcinoma epidermóide invasor}

Todas as pacientes que apresentem citopatologia sugestiva de lesão de alto grau não podendo excluir microinvasão ou carcinoma epidermóide invasor, na Unidade da Atenção Básica, devem ser encaminhadas imediatamente à Unidade de Referência de Média Complexidade para colposcopia como conduta inicial.
A definição histopatológica de invasão se impõe na Unidade de Referência de Média Complexidade.

Quando a colposcopia for satisfatória ou insatisfatória e não mostrar lesão, a conduta recomendada é a biopsia. Se o resultado da biopsia for de carcinoma invasor, a paciente deverá ser encaminhada para o Centro Especializado de Alta Complexidade. Se o resultado de biopsia não confirmar carcinoma invasor, realizar conização, desde que não haja indícios clínicos de invasão, situação na qual a paciente deverá ser encaminhada ao Centro Especializado de Alta Complexidade.

Quando a colposcopia for satisfatória ou insatisfatória e não mostrar lesão, indicar conização e recomendação específica.

As condutas recomendadas, para as pacientes com lesōes de alto grau, não podendo excluir microinvasão ou carcinoma epidermóide invasor, são apresentadas na Figura 8.

\subsubsection{Recomendações específicas de acordo com o laudo histopatológico}

Considerando-se os laudos histopatólogicos obtidos, através dos métodos incisionais e/ou excisionais, realizados na Unidade de Referência de Média Complexidade, as recomendações específicas a serem adotadas são apresentadas na Figura 9.

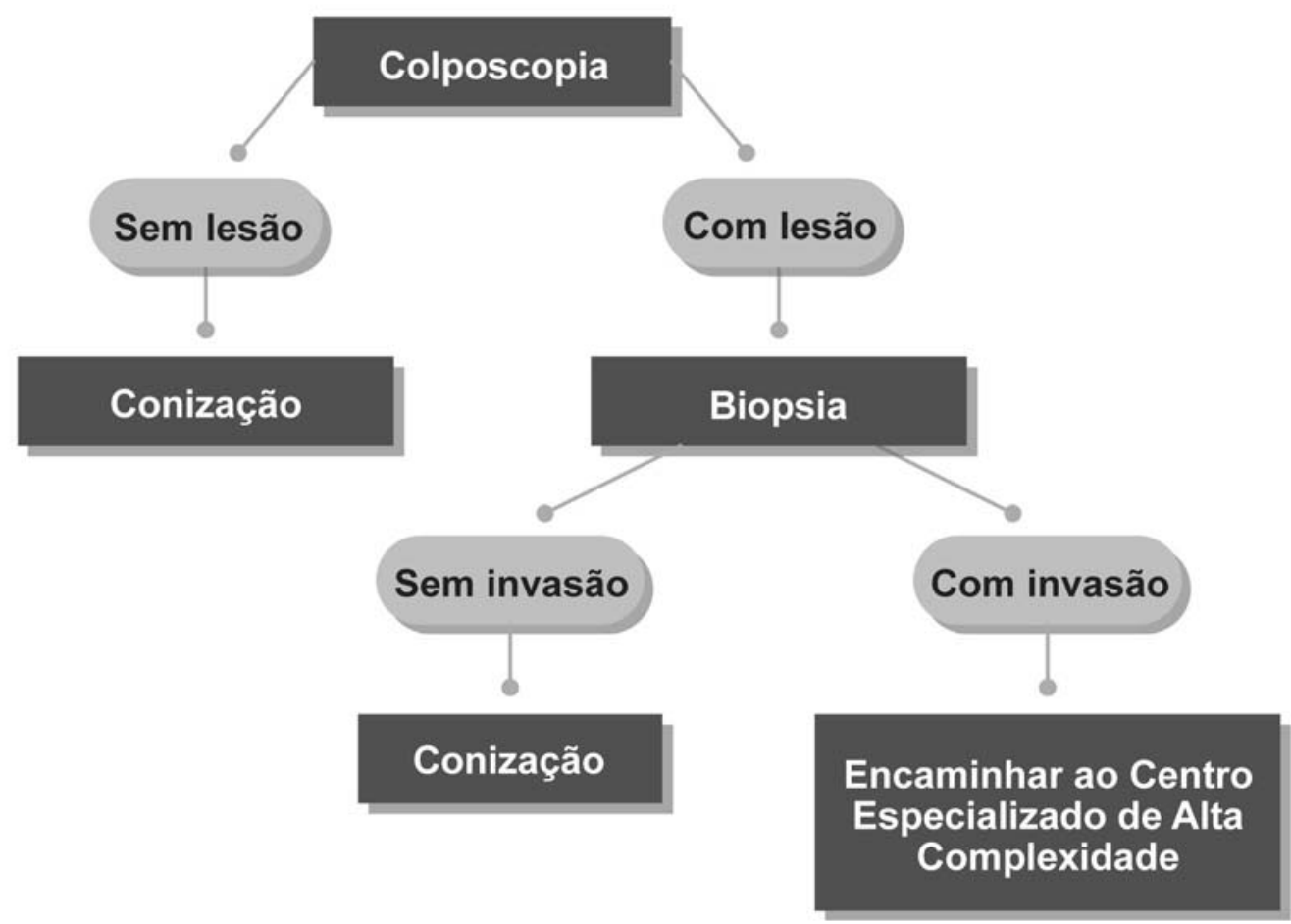

Nas mulheres com mais de 40 anos, deve-se proceder à investigação endometrial e anexial, assim como nas mulheres mais jovens com sangramento transvaginal anormal.

A recomendação da realização de conização, como conduta para as colposcopias sem lesão, baseia-se na literatura científica que revela uma grande correlação cito-histopatológica e com o fato de grande parte das colposcopias realmente não apresentarem lesão.

Figura 7. Recomendações para condutas frente às pacientes com adenocarcinoma in situ / invasor 


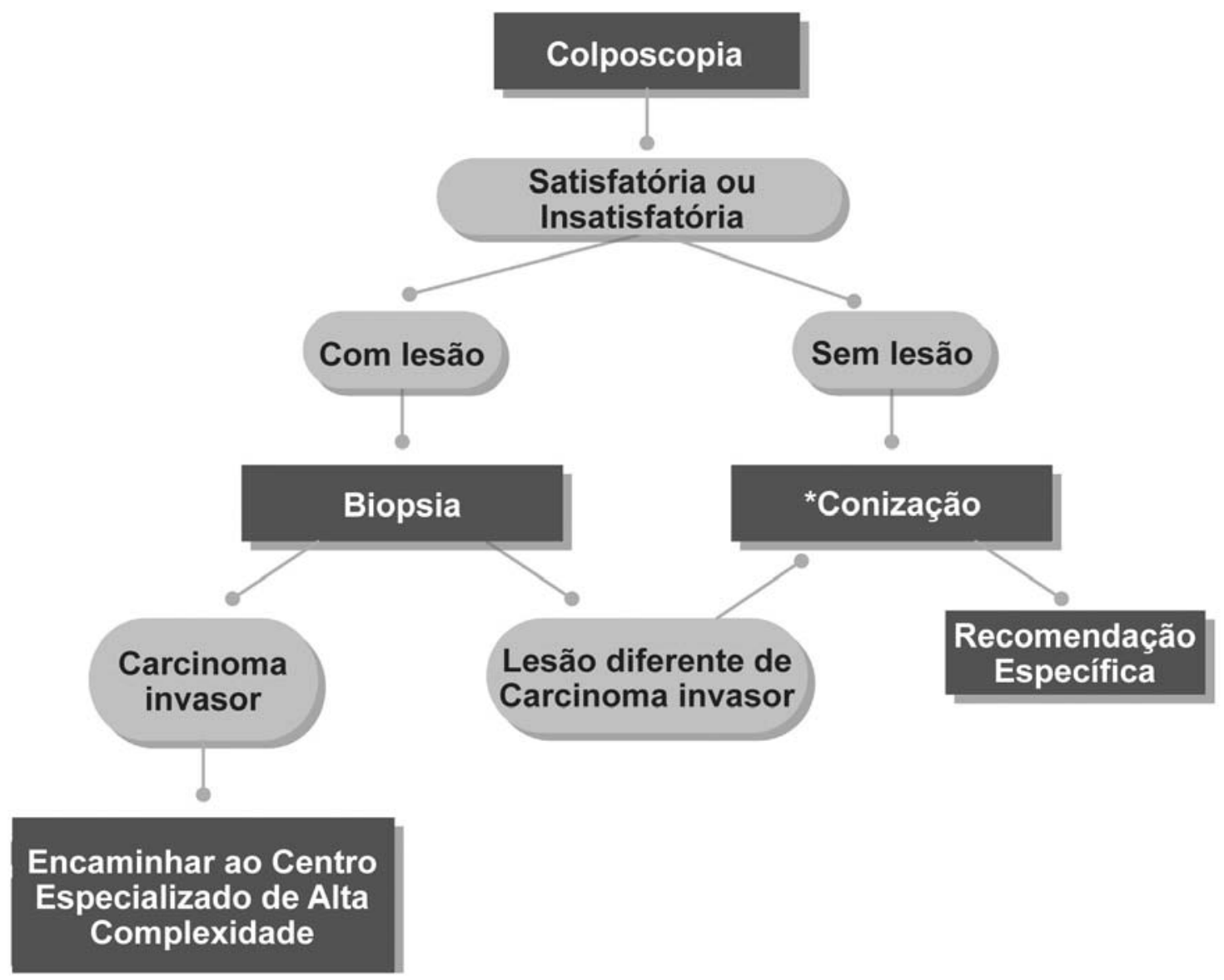

*Exceto nos casos com indícios clínicos sugestivos de invasão, os quais serão encaminhados ao Centro Especializado de Alta Complexidade.

Figura 8. Recomendações para condutas frente às pacientes com lesão de alto grau, não podendo excluir microinvasão ou carcinoma epidermóide invasor

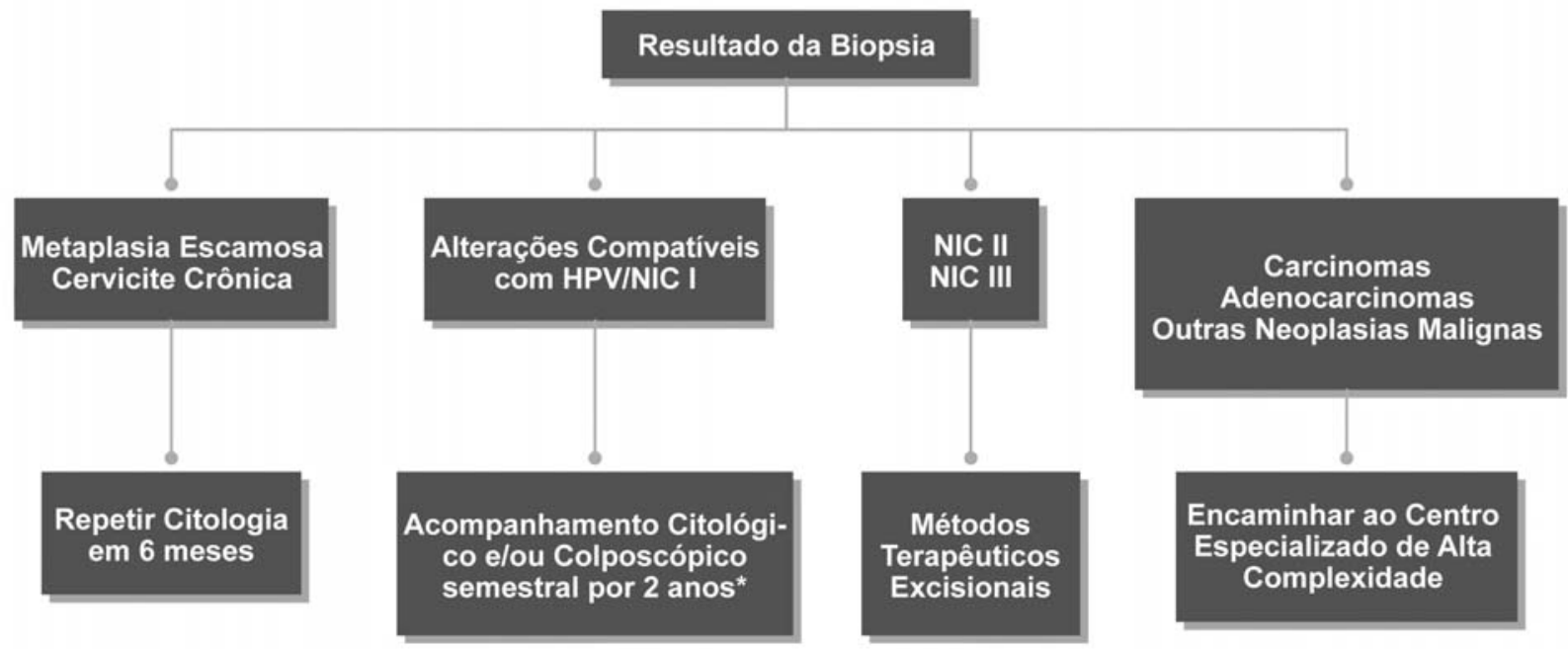

*Caso haja persistência das alterações citológicas e/ou colposcópicas, está indicado exerese da Zona de Transformação.

Figura 9. Recomendações específicas de acordo com o laudo histopatológico 


\subsection{SITUAÇ̃̃ES ESPECIAIS}

\subsubsection{Mulheres pós-menopausa}

A conduta a ser adotada na Unidade da Atenção Básica não se altera para as pacientes em pós-menopausa, exceto nas atipias celulares de significado indeterminado e neoplasia intra-epitelial de baixo grau, quando associada à atrofia genital constatada pelo exame clínico e/ou citológico, já que nesses casos há uma incidência maior de citologia falso-positiva. Nessa situação, a estrogenização, caso não haja contra-indicação, e a repetição citológica, se impõem, na Unidade da Atenção Básica.

A estrogenização pode ser feita mediante a administração oral de estrogênios conjugados por sete dias, com a realização do exame citopatológico em até uma semana após o término do esquema ou a administração tópica de estrogênio creme por sete dias, com realização do exame citopatológico entre o $3^{\circ}$ e o $7^{0}$ dia após o término do esquema. As pacientes que apresentarem anormalidade citológica, após estrogenização, deverão ser encaminhadas à Unidade de Referência de Média Complexidade para colposcopia imediata e conduta. Naquelas que apresentarem resultado negativo, uma nova citologia deverá ser realizada em seis meses, na Unidade da Atenção Básica. Depois de duas citologias consecutivas negativas, a paciente deverá retornar à rotina de rastreamento.

As pacientes em pós-menopausa, uma vez na Unidade de Referência de Média Complexidade, serão submetidas às condutas anteriormente apresentadas nesse documento.

\subsubsection{Mulheres imunodeprimidas}

As mulheres imunodeprimidas, com resultado citológico alterado, têm risco aumentado de apresentarem lesão histopatológica mais grave ou progressão da lesão, incluindo a evolução para o câncer do colo do útero. Recomenda-se, portanto, encaminhálas à Unidade de Referência de Média Complexidade para colposcopia imediata.

Considera-se paciente imunodeprimida aquela portadora do HIV, usuária de corticóides, transplantada, entre outras.

Nas mulheres portadoras do HIV, as lesões precursoras apresentam envolvimento cervical mais extenso e com mais frequiência envolvem outros órgãos do trato genital inferior, tais como: a vagina, a vulva e a região perianal. A investigação da paciente com citologia sugestiva de lesōes de baixo e alto graus e o respectivo tratamento devem ser acompanhados de introdução de terapia anti-retroviral eficaz. Isso reduz o risco de recorrências, de progressão de lesões existentes e de persistência pós-tratamento.

As pacientes imunodeprimidas, uma vez na Unidade de Referência de Média Complexidade, serão submetidas às condutas anteriormente apresentadas nesse documento. Quando de retorno à Unidade da Atenção Básica, deverão ser rastreadas anualmente por toda a vida, em decorrência de maior risco de recidiva.

\subsubsection{Gestantes}

Estudos mostram que o risco de progressão de uma lesão de alto grau para carcinoma invasor, durante o período gestacional, é extremamente baixo e a regressão espontânea após o parto é relativamente freqüente ${ }^{31-34 .}$

Mulheres gestantes com o laudo citopatológico alterado devem seguir a conduta recomendada para as pacientes não-grávidas, na Unidade da Atenção Básica.

$\mathrm{Na}$ Unidade de Referência de Média Complexidade, o objetivo principal é afastar a possibilidade de lesão invasora, portanto, diante de uma colposcopia satisfatória ou insatisfatória mostrando lesão sugestiva de invasão, a biopsia se impõe. Caso contrário, isto é, na presença de lesão colposcópica sugestiva de lesão de alto grau ou de menor gravidade, a paciente permanecerá em controle colposcópico e citológico na Unidade de Referência de Média Complexidade, trimestralmente, até o parto. Confirmada a invasão pela biopsia, a paciente deverá ser encaminhada ao Centro Especializado de Alta Complexidade. Se a colposcopia for insatisfatória não mostrando lesão, uma nova colposcopia deve ser realizada em três meses, pela possibilidade de a colposcopia se tornar satisfatória na evolução da gravidez.

Toda lesão colposcópica associada à citologia de invasão deve ser biopsiada.

A conduta obstétrica, em princípio, para a resolução da gravidez, não deve ser modificada em decorrência dos resultados colposcópicos, citopatológicos e histopatológicos, exceto nos casos de franca invasão ou obstrução do canal do parto.

Após o parto, as reavaliações colposcópica e citopatológica deverão ser realizadas, entre seis e oito semanas, na Unidade de Referência de Média Complexidade.

\subsubsection{Adolescentes}

De acordo com a Lei no 8069, de 13/7/1990, que dispóe sobre o Estatuto da Criança e do Adolescente, considera-se criança a pessoa até 12 anos de idade incompletos, e adolescente aquela entre 12 e 18 anos de idade. 
ORGANIZAÇÃO E REDAÇÃO FINAL

Fátima Meirelles Pereira Gomes - MS/INCA/ CONPREVIDivisão de Atenção Oncológica; Giani Silvana Schwengber Cezimbra - MS/ Área Técnica de Saúde da Mulher; José Antonio Marques - Fundação Oncocentro de São Paulo (FOSP); Jurandyr Moreira de Andrade - Federação Brasileira da Associação de Ginecologia e Obstetrícia (FEBRASGO); Lucilia Maria Gama Zardo - MS/INCA/DIPAT/SITEC; Luiz Carlos Zeferino - Centro de Atenção Integral à Saúde da Mulher da Universidade Estadual de Campinas (CAISM/ UNICAMP); Marco Antonio Teixeira Porto - MS/INCA/ Coordenação de Açôes Estratégicas; Maria Fátima de Abreu - MS/INCA/CONPREVIDivisão de Atenção Oncológica; Neil Chaves de Souza - SMS-RJ - PAM Manoel Guilherme da Silveira ; Olímpio Ferreira Neto - MS/INCA/Hospital do Câncer II.

\section{LISTA DOS PARTICIPANTES NAS}

\section{DIFERENTES ETAPAS DO TRABALHO}

Afrânio Coelho, Alexandre José Peixoto Donato, Alvaro Piazetta Pinto, Ana Cristina Lima Pinheiro, Ana Maria Castro Morillo, Andreia Xavier Polastro, Antonio Luiz Almada Horta, Carlos Alberto Fernandes Ramos, Carlos Alberto Ribeiro, Carlos Alberto Temes de Quadros, Carlos Eduardo Polastri Claro, Celso di Loreto, Claudia Jacinto, Claudia Marcia Pereira Passos, Claudio Aldila Oliveira da Costa, Claudio Bernardo H.Pereira Oliveira, Cleide Regina da Silva Carvalho, Clovis dos Santos Andrade, Deise de Carvalho Dias, Delia Maria Rabelo, Delly Cristina Martins, Denise Barbosa, Denise José Pereira, Élbio Cândido de Paula, Elias Fernando Miziara, Elizabeth Cristina de Souza Mendes, Elsio Barony de Oliveira, Elza Baia de Brito, Elza Gay Pereyra, Estefania Mota Araripe Pereira, Ethel Cristina Souza Santos, Euridice Figueiredo, Fabio Russomano, Fatima Edilza Xavier de Andrade, Fatima Meirelles Pereira Gomes, Fatima Regina Gomes Pinto, Fernando Azeredo, Francisco de Assis Leite Filho, Francisco José Batista da Silva, Gerson Botacini das Dores, Giani Silvana Schwengber Cezimbra, Gleyce Juventelles de Oliveira Anunciação, Gulnar Azevedo e Silva Mendonça, Gutemberg Leão de Almeida Filho, Henrique de Oliveira Costa, Hercilio Fronza Júnior, Ilsa Prudente, Ilzia Doraci Lins Scapulatempo, Isa Maria Mello, Isabel Cristina Chuvalis Doval, Ivana Porto Ribeiro, João Batista da Silva, Joel Takashi Totsugui, Jorge Henrique Gomes de Mattos, Jose Anselmo Cordeiro Lopes, José Antonio Marques, José Eluf Neto, José Guilhermo Berenguer Flores, José Helvécio Kalil, José Mauro Secco, Josefina de Andrade Monteiro de Barro, Jucelei Escandela, Jupira Mesquita, Jurandyr
Moreira de Andrade, Katia Regina Santos Lima, Laudycéia de S. Oliveira, Leda Pereira de Barcelos, Leonel Ricardo Curcio Junior, Letícia Katz, Liana Ariza, Luciane Maria Oliveira Brito, Lucilia Maria Gama Zardo, Luiz Cálice Cintra, Luiz Carlos de Lima Ferreira, Luiz Carlos Zeferino, Luiz Claudio Santos Thuler, Luiz Fernando Bleggi Torres, Luiz Martins Collaço, Manoel Afonso Guimarães Gonçalves, Marco Antônio Oliveira Apolinário, Marco Antonio Teixeira Porto, Marcos André Félix da Silva, Marcus Valério Frohe de Oliveira, Maria Beatriz Kneipp Dias, Maria da Conceição Aguiar Lyra, Maria Diva Lima, Maria do Carmo Esteves da Costa, Maria Fátima de Abreu, Maria Isabel do Nascimento, Maria José Camargo, Maria José de Souza Ferreira, Maria Lúcia Prest Martelli, Maria Midori Piragibe, Maria Odete Abrantes Correia Lopes, Maria Raymunda de Albuquerque Maranhão, Marieta Maldonado, Marilene Filgueiras Nascimento, Marina Andrade Amaral, Marina Lang Dias Rego, Maristela V. Peixoto, Maura Raquel Ferreira Sousa Vidal, Midori Piragibe, Mônica de Assis, Morgana Martins dos Santos, Nabiha Taha, Neil Chaves de Souza, Nelson Cardoso de Almeida, Nelson Valente Martins, Ney da Silva Pereira, Nilza Maria Sobral Rebelo Horta, Norma Império Meyrelles, Olimpio F. de Almeida Neto, Paula Fernandes de Brito, Paula Maldonado, Paulo Giraldo, Paulo Sergio Peres Fonseca, Renata Aranha, Risoleide Marques de Figueiredo, Roberto Junqueira de Alvarenga, Ronaldo Correa F. da Silva, Ronaldo L. Rangel Costa, Roseli Monteiro da Silva, Rui Luzzaito, Sergio M. Bicalho, Sérgio Tavolaro Pereira, Sheila Rochelin, Sônia Maria Lima S. Marcena, Sueli Aparecida Maeda, Tânia Maria Cruz Werton Veras, Terezinha Castelo Branco Carvalho, Therezinha Sanfim Cardoso, Valeria de Andrade, Valeria Hora de Mello, Vânia Reis Girianelli, Vera Lucia Motta da Fonseca, Virgílio Augusto G. Parreira, Virginia Borges Nassralla, Wanuzia Queila de Miranda, Wilhermo Torres, Wilna Krepke Leiros Dias.

\section{BIBLIOGRAFIA}

1. Instituto Nacional de Câncer; Ministério da Saúde. Estimativa 2006: incidência de câncer no Brasil. Rio de Janeiro (Brasil): INCA; 2005.

2. Instituto Nacional de Câncer; Ministério da Saúde. Inquérito domiciliar sobre comportamentos de risco e morbidade referida de doenças e agravos não transmissíveis: Brasil, 15 capitais e Distrito Federal, 2002-2003. Rio de Janeiro (Brasil): INCA; 2004.

3. Instituto Brasileiro de Geografia e Estatística. PNAD 2005: Pesquisa Nacional por Amostra de Domicílios. IBGE. 
4. Solomon D, Davey D, Kurman R, Moriarty A, O'Connor D, Prey M. The 2001 Bethesda System: terminology for reporting results of cervical cytology. JAMA. 2002 Apr 24;287(16):2114-9.

5. Koss GL, Melamed RM. Koss' diagnostic cytology and its histopathologic bases. 5th ed. Philadelphia: Lippincott Williams \& Wilkins; 2006.

6. Instituto Nacional de Câncer; Ministério da Saúde. Periodicidade de realização do exame preventivo do câncer do colo do útero: normas e recomendaçōes do INCA. Rev Bras Cancerol. 2002;48(1):13-5.

7. Wright TC Jr, Cox JT, Massad LS, Twiggs LB, Wilkinson EJ; ASCCP-Sponsored Consensus Conference. 2001 Consensus Guidelines for the management of women with cervical cytological abnormalities. JAMA. 2002 Apr 24;287(16):2120-9.

8. Solomon D, Frable WJ, Vooijs GP, Wilbur DC, Amma NS, Collins RJ, et al. ASCUS and AGUS criteria. International Academy of Cytology Task Force summary. Diagnostic Cytology Towards the 21st Century: An International Expert Conference and Tutorial. Acta Cytol.1998;42(1):16-24.

9. Solomon D, Schiffman M, Tarone R; ALTS Study Group. Comparison of three management strategies for patients with atypical squamous cells of undetermined significance: baseline results from a randomized trial. J Natl Cancer Inst. 2001 Feb 21;93(4):293-9.

10. Ferris DG, Wright TC Jr, Litaker MS, Richart RM, Lorincz AT, Sun XW, et al. Triage of women with ASCUS and LSIL on Pap smear reports: management by repeat Pap smear, HPV DNA testing, or colposcopy? J Fam Pract. 1998;46(2):125-34.

11.Manos MM, Kinney WK, Hurley LB, Sherman ME, ShiehNgai J, Kurman RJ, et al. Identifying women with cervical neoplasia: using human papillomavirus DNA testing for equivocal Papanicolaou results. Identifying women with cervical neoplasia. JAMA. 1999;28(17):1605-10. Comment in: JAMA. 1999 May 5;281(17):1645-7.

12. Bergeron C, Jeannel D, Poveda J, Cassonnet P, Orth G. Human papillomavirus testing in women with mild cytologic atypia. Obstet Gynecol. 2000 Jun;95(6 Pt 1):821-7.

13. Wright TC Jr, Lorincz A, Ferris DG, Richart RM, Ferenczy A, Mielzynska I, et al. Reflex human papillomavirus deoxyribonucleid acid testing in women with abnormal Papanicolaou smears. Am J Obstet Gynecol. 1998;178(5):962-6.

14. Mitchell MF, Schottenfeld D, Tortolero-Luna G, Cantor SB, Richards-Kortum R. Colposcopy for the diagnosis of squamous intraepithelial lesion: a meta-analysis. Obstet Gynecol. 1998;91(4):626-31.

15. Jones BA, Novis DA. Follow-up of abnormal gynecologic cytology: a college of American pathologists Q-probes study of 16132 cases from 306 laboratories. Arch Pathol Lab Med. 2000;124(5):665-71.

16. Lonky NM, Sadeghi M, Tsadik GW, Petitti D. The clinical significance of the poor correlation of cervical dysplasia and cervical malignancy with referral cytologic results. Am J Obstet Gynecol.1999;18(3)1:560-6.

17. Ronnett BM, Manos MM, Ransley JE, Fetterman BJ, Kinney WK, Hurley LB, et al. Atypical glandular cells of undetermined significance (AGUS): cytopathologic features, histopathologic results, and human papillomavirus DNA detection. Hum Pathol. 1999;30(7):816-25.

18. Kennedy AW, Salmieri SS, Wirth SL, Biscotti CV, Tuason LJ, Travarca MJ. Results of the clinical evaluation of atypical glandular cells of undetermined significance (AGCUS) detected on cervical cytology screening. Gynecol Oncol. 1996;63(1):14-8.

19. Valdini A, Vaccaro C, Pechinsky G, Abernathy V. Incidence and evaluation of an AGUS Papanicolaou smear in primary care. J Am Board Farm Pract. 2001;14:172-7.

20. Duska LR, Flynn CF, Chen A, Whall-Strojwas D, Goodman A. Clinical evaluation of atypical glandular cells of undetermined significance on cervical cytology. Obstet Gynecol.1998 Feb;91(2):278-82.

21. Taylor RR, Guerrieri JP, Nash JD, Henry MR, O'Connor DM. Atypical cervical cytology: colposcopic follow-up using the Bethesda System. J Reprod Med. 1993;38(6):443-7.

22. Goff BA, Atanasoff P, Brown E, Muntz HG, Bell DA, Rice LW. Endocervical glandular atypia in Papanicolaou smears. Obstet Gynecol.1992;79:101-4.

23. Zweizig S, Noller k, Reale F, Collis S, Resseguie L. Neoplasia associated with atypical glandular cells of undetermined significanceon cervical cytology. Gynecol Oncol.1997;65(2):314-8.

24. Jones BA, Davey DD. Quality management in gynecologic cytology using interlaboratory comparison. Arch Pathol Lab Med. 2000 May;124:672-81.

25. Kinney WK, Manos MM, Hurley LB, Ransley JE. Where's the high-grade cervical neoplasia? The importance of minimally abnormal Papanicolaou diagnoses. Obstet Gynecol. 1998 Jun;91(6):973-6.

26. Massad LS, Collins YC, Meyer PM. Biopsy correlates of abnormal cervical cytology classified using the Bethesda System. Gynecol Oncol. 2001 Sep;82:516-22.

27. Laverty CR, Farnsworth A, Thurloe J, Bowditch R. The reliability of a cytological prediction of cervical adenocarcinoma in situ. Aust N Z J Obstet Gynaecol. 1988;28:307-12. 
28. Lee KR, Manna EA, St John T. Atypical endocervical glandular cells: accuracy of cytologic diagnosis. Diagn Cytopathol.1995 Oct;13:202-8.

29. van Aspert-van Erp AJ, Smedts FM, Vooijs GP. Severe cervical glandular cell lesions and severe cervical combined lesions: predictive value of the Papanicolaou smear. Cancer. 2004 Aug 25;102(4):210-7.

30. Ahdoot D, Van Nostrand KM, Nguyen NJ, Tewari DS, Kurasaki T, DiSaia PJ, et al. The effect of route of delivery on regression of abnormal cervical cytologic findings in the postpartum period. Am J Obstet Gynecol.1998 Jun;178(6):1116-20.

31. Yost NP, Santoso JT, McIntire DD, Iliya FA. Postpartum regression rates of antepartum cervical intraepithelial neoplasia II and III lesions. Obstet Gynecol. 1999 Mar;93(3):359-62.

32. Parakevaidis E, Koliopoulos G, Kalantaridou S, Pappa L, Navrozoglou I, Zikopoulos K, et al. Management and evolution of cervical intraepithelial neoplasia during pregnancy and postpartum. Eur J Obstet Gynecol Reprod Biol. 2002 Aug 5;104(1):67-9.

33. Siristatidis Ch, Vitoratos N, Michailidis E, Syciotis C, Panagiotopoulos N, Kassanos D, et al. The role of the mode of delivery in the alteration of intrapartum pathological cervical cytologic findings during the postpartum period. Eur J Gynecol Oncol. 2002;23(4):358-60.

34. Commonwealth of Austrália. Screening to prevent cervical cancer: guidelines for the management of asymptomatic women with screen detected adnormalities. 2005.

35. Mount SL, Papillo JL. A study of 10.296 pediatric and adolescent Papanicolaou smear diagnoses in northern New England. Pediatrics.1999 Mar;103(3):539-45.

36. Wright JD, Davila RM, Pinto KR, Merritt DF, Gibb RK, Rader JS, et al. Cervical dysplasia in adolescents. Obstet Gynecol. 2005;106:115-20. 


\section{GLOSSÁRIO}

Centro Especializado de Alta Complexidade - Considera-se como Centro Especializado de Alta Complexidade em Oncologia os hospitais definidos pela portaria SAS/MS no741 de 19 de dezembro de 2005 como Unidades de Alta Complexidade em Oncologia, Centros de Assistência de Alta Complexidade em Oncologia (CACON) e Centros de Referência de Alta Complexidade em Oncologia.

Unidade de Alta Complexidade em Oncologia - "hospital que possua condições técnicas, instalações físicas, equipamentos e recursos humanos adequados à prestação de assistência especializada de alta complexidade para diagnóstico definitivo e tratamento dos cânceres mais prevalentes no Brasil."

CACON - "hospital com condições técnicas, instalaçōes físicas, equipamentos e recursos humanos adequados à prestação de assistência especializada de alta complexidade para diagnóstico definitivo e tratamento definitivo para todos os tipos de câncer".

Centro de Referência de Alta Complexidade em Oncologia "CACON" que exerça o papel auxiliar, de caráter técnico, ao Gestor do SUS nas políticas de Atenção Oncológica."

Colposcopia - Método óptico para exame do trato genital inferior iluminado com magnificação intermediária entre o olho desarmado e o pequeno aumento do microscópio. Recomendase que a colposcopia seja sempre diferencial, isto é, não se restrinja à simples observação e descrição dos achados, mas que seja suficientemente rigorosa e pormenorizada para melhor dirigir $\mathrm{o}$ ato da biopsia localizando o epicentro da lesão, o ponto mais significante, aquele com maior probabilidade de corresponder ao substrato histopatológico sugerido pelo achado colposcópico.

Colposcopia insatisfatória - Considera-se colposcopia insatisfatória o exame que apresente, pelo menos uma, das seguintes condiçõos: Junção escamo-colunar não visível, inflamação severa, atrofia severa, trauma ou cérvice não-visível.

Colposcopia satisfatória - Considera-se satisfatória a colposcopia que não apresente, pelo menos uma, das seguintes condiçôes: Junção escamo-colunar não-visível, inflamação severa, atrofia severa, trauma ou cérvice não-visível.

Colposcopia sem lesão - Considera-se sem lesão o exame sem achados colposcópicos anormais ou sugestivos de câncer invasivo.

Conduta Específica - Qualquer medida tomada diante de um resultado citológico.

Métodos Excisionais - Estes métodos incluem tanto a exerese completa da Zona de Transformação, como a conização.

Conização - Remoção da zona de transformação e de parte variável do canal cervical. A extensão da excisão depende da gravidade da lesão em tratamento, da idade da paciente, da visualização da junção escamo-colunar, entre outros fatores. A decisão quanto à extensão deve ser tomada em função do texto de "Condutas preconizadas" e de acordo com o julgamento do médico para cada caso.

Recomendação Específica - Qualquer conduta tomada diante de um resultado histopatológico.

Terminologia colposcópica - Nomenclatura para laudos colposcópicos, sendo recomendada a adoção da Terminologia Colposcópica da IFCPC - Barcelona 2002.

Unidade da Atenção Básica - Unidades que compõem a estrutura básica de atendimento aos usuários do SUS. Podem ser:

- Unidade Saúde da Família - Unidade pública específica para a prestação de assistência em atenção contínua programada nas especialidades básicas e com equipe multidisciplinar para desenvolver as atividades que atendam às diretrizes da estratégia Saúde da Família do Ministério da Saúde.

- Posto de Saúde - Unidade destinada à prestação de assistência a uma determinada população, de forma programada ou não, por profissional de nível médio, com presença intermitente ou não de profissional médico;

- Centro de Saúde/ Unidade da Atenção Básica - Unidade para a realização de atendimentos de atenção básica e integral a uma população, de forma programada ou não, nas especialidades básicas, podendo oferecer assistência odontológica e de outros profissionais de nível superior. A assistência deve ser permanente e prestada por médicos generalistas ou especialistas nessas áreas. Pode ou não oferecer SADT e pronto atendimento 24 horas;

- Unidade móvel fluvial - Barco/navio, equipado como unidade de saúde, contendo, no mínimo, um consultório médico e uma sala de curativos, podendo ter consultório odontológico.

- Unidade terrestre móvel para atendimento médico/ odontológico - Veículo automotor equipado, especificamente, para prestação de atendimento ao paciente.

- Unidade mista - Unidade de saúde básica destinada à prestação de atendimento em atenção básica e integral à Saúde, de forma programada ou não, nas especialidades básicas, podendo oferecer assistência odontológica e de outros profissionais, com unidade de internação, sob administração única. A assistência médica deve ser permanente e prestada por médico especialista ou generalista.

- Ambulatório de Unidade Hospitalar - Serviço de atenção básica que funciona em hospitais.

Unidade de Referência de Média Complexidade - Unidade de Referência para o tratamento e acompanhamento das Condutas Preconizadas de alterações pré-malignas ou malignas no exame citopatológico. A média complexidade é um dos três níveis de atenção à Saúde, considerados no âmbito do SUS. Compõe-se por açóes e serviços que visam a atender aos principais problemas de saúde e agravos da população, cuja prática clínica demande disponibilidade de profissionais especializados e o uso de recursos tecnológicos de apoio diagnóstico e terapêutico. A atenção média foi instituída pelo Decreto no 4.726 de 2003, que aprovou a estrutura regimental do Ministério da Saúde. Suas atribuições estão descritas no Artigo 12 da proposta de regimento interno da Secretaria de Assistência à Saúde. Os grupos que compõem os procedimentos de média complexidade do Sistema de Informaçōes Ambulatoriais são os seguintes: 1) procedimentos especializados realizados por profissionais médicos, outros de nível superior e nível médio; 2) cirurgias ambulatoriais especializadas; 3) procedimentos traumato-ortopédicos; 4) açôes especializadas em odontologia; 5) patologia clínica; 6) 
anatomopatologia e citopatologia; 7) radiodiagnóstico; 8) exames ultra-sonográficos; 9) diagnose; 10) fisioterapia;11) terapias especializadas;12) próteses e órteses; 13) anestesia. $\mathrm{O}$ gestor deve adotar critérios para a organização regionalizada das açōes de média complexidade, considerando a necessidade de qualificação e especialização dos profissionais para o desenvolvimento das açóes; os dados epidemiológicos e sociodemográficos de seu município; a correspondência entre a prática clínica e a capacidade resolutiva diagnóstica e terapêutica; a complexidade e o custo dos equipamentos; a abrangência recomendável para cada tipo de serviço; economias de escala e métodos e técnicas requeridos para a realização das açôes. 